OPEN ACCESS

Edited by:

Xucong $L V$,

Fuzhou University, China

Reviewed by:

Du Zhu,

Jiangxi Science and Technology Normal University, China

Giacomo Zara,

University of Sassari, Italy

*Correspondence.

Jeong-Ah Seo

sja815@ssu.ac.kr

Specialty section:

This article was submitted to

Food Microbiology,

a section of the journal

Frontiers in Microbiology

Received: 26 February 2021 Accepted: 25 May 2021

Published: 24 June 2021

Citation:

Farh ME-A, Abdellaoui N and Seo J-A (2021) pH Changes Have

a Profound Effect on Gene

Expression, Hydrolytic Enzyme

Production, and Dimorphism

in Saccharomycopsis fibuligera.

Front. Microbiol. 12:672661.

doi: 10.3389/fmicb.2021.672661

\section{pH Changes Have a Profound Effect on Gene Expression, Hydrolytic Enzyme Production, and Dimorphism in Saccharomycopsis fibuligera}

\author{
Mohamed El-Agamy Farh, Najib Abdellaoui and Jeong-Ah Seo* \\ School of Systems Biomedical Science, Soongsil University, Seoul, South Korea
}

Saccharomycopsis fibuligera is an amylolytic yeast that plays an important role within nuruk (a traditional Korean fermentation starter) used for the production of makgeolli (Korean rice wine), which is characterized by high acidity. However, the effect of $\mathrm{pH}$ change (neutral to acidic) on the yeast cell to hyphal transition and carbohydratehydrolyzing enzyme activities for $S$. fibuligera has not been investigated yet. In this study, S. fibuligera strains were cultured under the different $\mathrm{pH}$ conditions, and the effect on the enzyme production and gene expression were investigated. An acidic $\mathrm{pH}$ induced a hyphal transition from yeast cell of $S$. fibuligera $\mathrm{KPH} 12$ and the hybrid strain KJJ81. In addition, both strains showed a gradual decrease in the ability to degrade starch and cellulose as the $\mathrm{pH}$ went down. Furthermore, a transcriptome analysis demonstrated that the $\mathrm{pH}$ decline caused global expression changes in genes, which were classified into five clusters. Among the differentially expressed genes (DEGs) under acidic $\mathrm{pH}$, the downregulated genes were involved in protein synthesis, carbon metabolism, and RIM101 and CAMP-PKA signaling transduction pathways for the yeast-hyphal transition. A decrease in $\mathrm{pH}$ induced a dimorphic lifestyle switch from yeast cell formation to hyphal growth in S. fibuligera and caused a decrease in carbohydrate hydrolyzing enzyme production, as well as marked changes in the expression of genes related to enzyme production and $\mathrm{pH}$ adaptation. This study will help to elucidate the mechanism of adaptation of $S$. fibuligera to acidification that occur during the fermentation process of makgeolli using nuruk.

Keywords: Saccharomycopsis fibuligera, nuruk, transcriptome analysis, yeast cell-hyphae transition, pH effect, starch and cellulose hydrolysis

\section{INTRODUCTION}

The Korean traditional wine makgeolli is made by fermenting the starch materials of rice (Jang, 1989; Yeo and Jeong, 2010). High-quality makgeolli is characterized by high acidity and alcohol content (Song et al., 2015). Over 100 traditional makgeolli brands are available, and they are worth millions of dollars on the market (Jang, 1989; Yeo and Jeong, 2010). To produce makgeolli, the fermentation starter nuruk needs to be prepared from several kinds of grains, especially rice grains, using airborne microorganisms. These microorganisms provide a source of several hydrolytic enzymes that are required for starch degradation during saccharification to produce glucose and 
other organic acids (Song, 2013; Yang et al., 2013; Bal et al., 2014, 2015; Kim et al., 2014; Park et al., 2016). Then, glucose is fermented by Saccharomyces cerevisiae to produce alcohol. Thus, the quality of alcohol in makgeolli critically depends on the characteristics of the nuruk used for fermentation. The saccharification capability is an essential index used to estimate the quality of the nuruk (Lee et al., 2017), and it is based on microorganisms that occupy the nucleus and produce hydrolytic enzymes (Lee et al., 2017). Currently, several nuruk-inhabiting fungi, yeasts, and bacteria have been isolated from traditional nuruk and used to make commercial nuruk products (Jo and Lee, 1997; Seo et al., 2007; Carroll et al., 2017).

Since nuruk ingredients are mainly composed of polysaccharides, predominant microorganisms capable of degrading polysaccharides in nuruk include filamentous fungi, such as Rhizopus oryzae and Aspergillus oryzae (Kim et al., 2014). Because of the temperature increase during fermentation, the heat-resistant strain A. oryzae has an advantage over the heat-labile strain R. oryzae (Yang et al., 2011). A. oryzae secretes amylases at high levels (Norihiro et al., 1989; Liu et al., 2014) and is thus an important fungus for the saccharification step (Yang et al., 2011, 2013; Song, 2013). There have also been attempts to use alternative and more beneficial and risk-free yeasts, such as Monascus (Shin et al., 2017) and Saccharomycopsis fibuligera (Park et al., 2014). Of the microorganisms involved in nuruk fermentation, another important microorganism is S. fibuligera, a member of Saccharomycotina, which is a subphylum of Ascomycota. S. fibuligera is characterized by a morphology-switching lifestyle known as dimorphism and can propagate by branched hyphal growth or yeast cell-like growth (Kurtzman and Smith, 2011). S. fibuligera is considered the best producer of amylolytic enzymes among all ascomycetous yeasts (de Mot et al., 1984). It was found to be a predominant yeast in various Asian fermentation starters, including nuruk in Korea (Bal et al., 2014; Carroll et al., 2017; Farh et al., 2017). It produces cellulose-degrading enzymes that play a key role in the saccharification process of lignocellulosic compounds (Ma et al., 2015; Van Zyl et al., 2016). Ethanol can be produced from carbohydrate-type substrates by cocultivation of $S$. fibuligera with ethanol producers such as S. cerevisiae and Zymomonas mobiliz (Abouzied and Reddy, 1987; Reddy and Basappa, 1996; Park et al., 2014).

Saccharification by nuruk mostly produces simple sugars. Glucose is mainly fermented by S. cerevisiae, while other sugars can be converted by other microorganisms into organic acids, resulting in a decline in $\mathrm{pH}$ from neutral to acidic. The $\mathrm{pH}$ is weakly basic to neutral at the starting point, suddenly becomes strongly acidic ( $\mathrm{pH} 3.31-2.96$ ), and slightly increases to 3.34 at the end of the fermentation process (Song et al., 2015). The dynamic $\mathrm{pH}$ change during fermentation could affect the growth, morphology and physiology of microorganisms involved in fermentation. Some microorganisms, such as Sclerotinia sclerotiorum, a plant necrotrophic pathogen, and Ustilago maydis, a filamentous and pathogenic form of the dimorphic biotrophic pathogen, grow well under acidic pH (Cotton et al., 2003), whereas other microorganisms, such as Candida albicans and Cryptococcus neoformans, show better growth under alkaline
pH conditions (Davis, 2003; O'Meara and Alspaugh, 2012). In addition, certain environmental microorganisms, such as Yarrowia lipolytica, favor dimorphic growth under ambient $\mathrm{pH}$ conditions but secrete protein-degrading enzymes under both acidic and alkaline pH conditions (Gonzalez-Lopez et al., 2002; Ruiz-Herrera and Sentandreu, 2002). Thus, environmental pH greatly influences the growth and activity of microorganisms. Microorganisms should sense the environmental $\mathrm{pH}$ and adapt to the conditions. To understand such adaptation, signaling cascades have been elucidated in various types of yeast and filamentous fungi at the molecular level, and they consist of MAPK, cAMP-PKA, and PacC/Rim101. MAPK and cAMPPKA have also been shown to regulate dimorphic growth and morphology-dependent pathogenesis (Leberer et al., 2001; Martínez-Espinoza et al., 2004; Kozubowski et al., 2009), whereas $\mathrm{PacC} / \mathrm{Rim} 101$ is involved in the regulation of adhesins, secretion of hydrolytic enzymes, and resistance to sodium and lithium (Cotton et al., 2003; Cornet and Gaillardin, 2014).

The $\mathrm{pH}$ change occurs during fermentation in the process of rice wine production. However, little is known about the effect of $\mathrm{pH}$ change on the growth and activity of microorganisms that grow in nuruk, such as $S$. fibuligera. In this study, we examined the effect of dynamic $\mathrm{pH}$ changes on the growth and physiology of S. fibuligera strain KPH12 and its newly discovered interspecies hybrid KJJ81 (Choo et al., 2016) by focusing on hydrolytic enzyme production, dimorphism, and gene expression. We provided evidence that KPH12 and the hybrid strain KJJ81 of S. fibuligera showed a morphological switch from the yeast-like form to hyphae-like elongated form in response to $\mathrm{pH}$ reduction. In addition, we identified the gene classes that were dramatically upregulated and downregulated due to the $\mathrm{pH}$ change occurring during fermentation.

\section{MATERIALS AND METHODS}

\section{Strains, Medium, and Growth Conditions}

Saccharomycopsis fibuligera KJJ81 and KPH12 strains were obtained from the original authors and used in this study. Here, the strains were routinely cultured on yeast extract peptone glucose (YPG) agar medium [2\% (w/v) glucose, $1 \%(w / v)$ yeast extract, $1 \%(\mathrm{w} / \mathrm{v})$ peptone, $2 \%(\mathrm{w} / \mathrm{v})$ agar, $\mathrm{pH}$ 6.0] which was modified with YEPD described as the previous report (Zhu et al., 2017). To test the $\mathrm{pH}$ effect on hydrolytic enzyme secretion, yeast cells of each strain $\left(10^{7} \mathrm{CFU} / \mathrm{ml}\right)$ were spotted on YPG agar buffered with phosphate buffer $(0.2 \mathrm{M}$ disodium hydrogen phosphate, and $0.2 \mathrm{M}$ sodium dihydrogen phosphate) for $\mathrm{pH} 7.0$ and citrate buffer $(0.1 \mathrm{M}$ citric acid, and $0.1 \mathrm{M}$ sodium citrate) for $\mathrm{pH} 6.0,5.0,4.0$, and 3.0. Three sets of buffered medium were inoculated with each strain; the first set was supplemented with $0.2 \%(\mathrm{w} / \mathrm{v})$ starch to assess starch degradation, the second set was supplemented with $0.2 \%(\mathrm{w} / \mathrm{v})$ carboxymethylcellulose (CMC) to estimate cellulose degradation, and the third set was supplemented with $2 \%(\mathrm{w} / \mathrm{v})$ skim milk to estimate protein degradation. The inoculated plates were incubated at $25^{\circ} \mathrm{C}$. Starch degradation was examined 3 days after incubation, and cellulose and protein degradation was examined 
5 days after incubation. To test the $\mathrm{pH}$ effect on dimorphic growth, yeast cells of both strains $\left(10^{6} \mathrm{CFU} / \mathrm{ml}\right)$ were cultured in YPG broth buffered as described above. The inoculated broths were incubated at $25^{\circ} \mathrm{C}$ with shaking $(200 \mathrm{rpm})$, and the cell morphology was examined $20 \mathrm{~h}$ after incubation; the proportion of yeast and hyphal cells was measured under a light microscope as described for Y. lipolytica (Ruiz-Herrera and Sentandreu, 2002). To test whether the $\mathrm{pH}$ or glucose concentration plays a role in hydrolytic enzyme production, particularly those for starch and cellulose degradation, the yeast cells of both strains were spotted on YPG agar [2\% (w/v)] plates supplemented with $0.1,0.5,2$, or $10 \%(\mathrm{w} / \mathrm{v})$ glucose. For each concentration, one type of substrate was added to estimate the degradation under three different buffered conditions: non-buffered, $\mathrm{pH}$ 7-buffered (using phosphate buffer), and pH 3-buffered (using citrate buffer) conditions. To test the effect of glucose or $\mathrm{pH}$ on dimorphism regulation, yeast cells of both strains were grown on YPG broth supplemented with the glucose concentrations set mentioned above under the same three buffered conditions. To confirm the involvement of cAMP-PKA in hyphal growth induction, the yeast cells of both strains were grown in $\mathrm{pH}$ 4-buffered YPG broth and agar supplemented with $600 \mu \mathrm{M}$ clozapine, a cAMP-PKA blocker. Clozapine was filter-sterilized and added to autoclaved medium after cooling. Cells were cultured on clozapine-free broths and plates as controls. The inoculated plates were incubated at $25^{\circ} \mathrm{C}$ for 5 days, while inoculated broths were incubated at $25^{\circ} \mathrm{C}$ with shaking $(200 \mathrm{rpm})$ for $20 \mathrm{~h}$. Hyphae development was examined using a light microscope.

\section{Scanning Electron Microscopy (SEM)}

Cells grown in YPG at different $\mathrm{pH}$ values starting from $\mathrm{pH}$ 7.0 to $\mathrm{pH} 3.0$ were collected by filtration and prepared for SEM examination as described previously (Staniszewska et al., 2013) with some modifications. Cells were suspended in fixation buffer [2.5\% (w/v) glutaraldehyde in $0.2 \mathrm{M}$ cacodylate buffer, $\mathrm{pH}$ 7.27.4] for $19 \mathrm{~h}$ at $4^{\circ} \mathrm{C}$. Samples were washed three times with 0.05 $\mathrm{M}$ sodium cacodylate buffer and subsequently suspended in $2 \%$ $(\mathrm{w} / \mathrm{v})$ osmium tetroxide and $0.1 \mathrm{M}$ cacodylate buffer $(1: 1, \mathrm{v} / \mathrm{v})$ for further fixation. Afterward, initial dehydration of cells was carried out by placing them in serial concentrations of 50 and $70 \%$ ethanol two times for 10 min each; $95 \%$ ethanol two times for $5 \mathrm{~min}$ each; and $100 \%$ ethanol two times for $1 \mathrm{~min}$ each. The final dehydration step was carried out by placing the samples in liquid $\mathrm{CO}_{2}$ for $90 \mathrm{~min}$ following the critical drying point method. Subsequently, the samples were subjected to silver coating under vacuum evaporation and examined by SEM.

\section{RNA-Seq Analysis}

To examine the whole transcriptional responses at each $\mathrm{pH}$ point, yeast cells were grown in YPG broth buffered at different $\mathrm{pH}$ values starting from 7.0 to 3.0 as described above. Cells were collected $18 \mathrm{~h}$ after incubation using vacuum filtration and rapidly stored at $-80^{\circ} \mathrm{C}$. Total RNA was prepared using an easy-spin total RNA extraction kit (iNtRON, South Korea), and sequencing of the total RNA was performed using an Illumina HiSeq 2500 instrument (Illumina, United States). Complementary DNA (cDNA) libraries were constructed at
Theragen Etex Bioinstitute (Seoul, South Korea). Pair-end RNA sequencing was performed by the company as reported previously (Mardis, 2008). Clean reads with high nucleotide accuracy were aligned with the genomes of either KPH12 or KJJ81 using Burrows-Wheeler Aligner (BWA) (Li and Durbin, 2009), and the total counting, expressed as RPKM (reads per kilobase of transcript, per million mapped reads), of the aligned fragments with the exon parts of the genes was determined using HTSeq (Anders et al., 2015). Counts were normalized to be expressed as RPKHM (reads per kilobase of transcript per hundred million mapped reads). The predicted protein was blasted against the NCBI database of non-redundant protein sequences (nr), Uniprot, and relative fungi RefSeq (i.e., S. cerevisiae, C. glabrata, $A$. oryzae, and $S$. pombe) databases with a E-value cutoff of $10^{-10}$. The raw data were filtered to remove the genes with zero reads among all samples and then transformed. Filtration and transformation were performed using the R package EdgeR (Robinson et al., 2010). A multidimensional scaling (MDS) plot was generated to show the variation in the expression of genes in the samples using the $\mathrm{R}$ package mixOmics (Rohart et al., 2017). Differentially expressed genes (DEGs) were determined by EdgeR, and $P$-values were controlled using the false discovery rate (FDR) (Benjamini and Hochberg, 1995) with a threshold lower than 0.05 .

For the clustering analysis, the average RPKM of the DEG lists of KPH12 and KJJ81 was clustered using the R package $M f u z z$. Five clusters were identified, and the fuzzifier coefficient was set to optimal. Following the clustering analysis, genes in each cluster with memberships lower than 0.5 were excluded and the remaining genes were subjected to a Gene Ontology (GO) enrichment analysis. GO enrichments of chosen clusters were filtered using the online public website REVIGO, and the resulting GO terms were visualized on Cytoscape.

\section{Reverse Transcription, PCR, and Quantitative Reverse Transcription-PCR (qRT-PCR)}

Prior to sending the RNA samples for RNA sequencing, aliquots were obtained for qRT-PCR validation of the gene of interest. Samples were kept at $-80^{\circ} \mathrm{C}$ until cDNA synthesis. Only samples at $\mathrm{pH} 7$ and $\mathrm{pH} 3$ were considered for the qRT-PCR validation for the gene of interest. cDNAs were synthesized using SuperScript III First-Strand (Invitrogen, United States) according to protocols provided by the manufacturer. Two micrograms of total RNA was mixed with the synthesis mixture at a volume of $20 \mu \mathrm{l}$, and the total volume was further diluted to $50 \mu \mathrm{l}$ for qRTPCR. Primer pairs of target genes were designed manually after aligning the gene sequences of the KPH12 and A and B genomes of KJJ81 using ClustalX2 (Larkin et al., 2007) and chemically synthesized (Macrogen Inc., Seoul, South Korea). The primers used in this study are listed in Supplementary Table 7. Quantitative real-time PCR (qRT-PCR) was carried out in a $10 \mu \mathrm{l}$ reaction volume consisting of $1 \mu \mathrm{l} \mathrm{cDNA}, 10 \mathrm{pmol}$ each of forward and reverse primers, $5 \mu \mathrm{l} 2 \mathrm{X} \mathrm{iQ}^{\mathrm{TM}} \mathrm{SYBR}^{\circledR}$ Green Supermix (BioRad, United States), and water to the final volume. Reactions were carried out using a CFX Connect ${ }^{\mathrm{TM}}$ 
Real-Time System (Bio-Rad, United States) in a Hard-Shell ${ }^{\circledR}$ 96-Well PCR Plate (Bio-Rad, United States). Among the wellknown housekeeping genes, $Y$-tubulin (TUB4) was selected as a control since it showed the most stable expression throughout all $\mathrm{pH}$ values. The following thermal cycler conditions were based on the manufacturer's recommendations: $3 \mathrm{~min}$ at $95^{\circ} \mathrm{C}$; 39 cycles at $95^{\circ} \mathrm{C}$ for $10 \mathrm{~s}$ and the proper annealing temperature for $30 \mathrm{~s}$; and one more cycle starting from 65 to $95^{\circ} \mathrm{C}$ for $5 \mathrm{~s}$ in $0.5^{\circ} \mathrm{C}$ increments for the melt curve analysis. The fluorescent product was detected during the annealing step of each cycle. Amplification, detection, and data analysis were performed on a CFX Manager ${ }^{\mathrm{TM}}$ Maestro version 1.0 (BioRad, United States). The relative fold differences in template abundance for each sample were determined by deducting the $C_{T}$ value of each gene expression from the $C_{T}$ value of TUB4.

\section{Statistical Analysis}

All data were analyzed using SPSS v. 26.0 software (SPSS Inc., Chicago, IL, United States). The statistical analysis includes comparison of group mean values with one-way ANOVA, and multiple comparisons among the groups with Scheffe post-hoc test at a significance level of $p<0.05$.

\section{Accession Numbers}

The RNA-seq raw data were deposited in the BioSample database of NCBI. The accession numbers are serial numbers from SRX10182890 to SRX10182919.

\section{RESULTS}

\section{Acidic pH but Not Glucose Causes Dimorphic Growth of S. fibuligera}

The effect of the $\mathrm{pH}$ change occurring during fermentation on the growth of $S$. fibuligera was investigated by growing $S$. fibuligera on YPG medium with different $\mathrm{pH}$ values, and we examined the morphology. Various $\mathrm{pH}$ values were used to mimic the $\mathrm{pH}$ change occurring during fermentation. Both the KPH12 and KJJ81 strains of S. fibuligera were grown on these plates and observed for morphological changes. For both the KPH12 and KJJ81 strains, when the $\mathrm{pH}$ of the medium was decreased from $\mathrm{pH} 7$ to $\mathrm{pH} 3$, the number of yeast-type cells gradually decreased, and concomitantly, the number of cells with hyphae increased (Figures 1A,C), indicating that a decline in the $\mathrm{pH}$ value induced the dimorphic growth of $S$. fibuligera. The single cells started to elongate at $\mathrm{pH} 6$ for both strains, indicating that hyphal growth is induced at $\mathrm{pH}$ 6. The interspecies hybrid strain KJJ81 was more responsive to the change in $\mathrm{pH}$ in terms of hyphal growth than KPH12 (Figures 1B,D).

Previously, we showed that the glucose concentration controls the dimorphic growth and hydrolytic enzyme production of S. fibuligera KPH12 and KJJ81 (Choo et al., 2016). During fermentation, the glucose concentration also changes because of starch or carbohydrate degradation in nuruk. Thus, to obtain a better understanding of the underlying cause of the dimorphic switch in the growth of S. fibuligera during fermentation, we examined the effect of glucose concentration on dimorphic changes. Under non-buffered conditions, both strains showed that the yeast-to-hyphae switch was induced when the glucose concentration changed from 0.1 to $10 \%$ (Figure 2 and Supplementary Figure 1). Yeast cells were dominant at the lowest glucose concentration, whereas hyphal cells were dominant at the highest glucose concentration (Figures 2A,D and Supplementary Figures 1A,C). Since $S$. fibuligera was grown under non-buffered conditions, the $\mathrm{pH}$ may have changed during the incubation and subsequently affected the yeast-to-hyphae switch. Thus, to assess the $\mathrm{pH}$ effect on the yeast-to-hyphae switch, we measured the $\mathrm{pH}$ at each glucose concentration $20 \mathrm{~h}$ after incubation with both strains and found that the $\mathrm{pH}$ was changed from neutral to weakly basic in $0.1 \%$ glucose, whereas the $\mathrm{pH}$ was acidic in $2-10 \%$ glucose (Supplementary Figures 1B,D). Both strains developed complete hyphal growth under buffered conditions at $\mathrm{pH} 3$ (Figures 2B,E and Supplementary Figures 1A,C) and yeast growth (Figures 2C,F and Supplementary Figures 1A,C) regardless of the glucose concentration. These results suggest that both carbohydrate degradation and dimorphism are regulated by $\mathrm{pH}$ change and not by glucose concentration.

\section{pH Change (Not Glucose Concentration) Has a Suppressive Effect on the Secretion of Hydrolytic Enzymes From S. fibuligera}

The effect of $\mathrm{pH}$ change on fermentation was examined by investigating the degradation of carbohydrates (e.g., starch and cellulose) and proteins by $S$. fibuligera. Both strains of $S$. fibuligera were grown on plates with different $\mathrm{pH}$ values ranging from 7 to 3 . The $\mathrm{pH}$ of the plate was maintained using specific buffers. S. fibuligera showed a significant difference in the ability to degrade starch and carbohydrates depending on pH. The KPH12 strain showed the highest activity for hydrolysis of starch and cellulose at $\mathrm{pH}$ 7. The hydrolytic activity gradually decreased with decreasing $\mathrm{pH}$ and reached its lowest level at pH 3 (Figure 3A). Similarly, the hybrid strain KJJ81 also showed a linear decline in carbohydrate degradation (Figure 3B). Next, we examined the effect of acidic $\mathrm{pH}$ values on protein degradation by both strains and found that protein degradation was low at acidic $\mathrm{pH}$ values for both strains (Figures 3A,B), indicating that acidic $\mathrm{pH}$ conditions suppress the ability of $S$. fibuligera to degrade proteins.

Next, we examined the effect of glucose concentration on carbohydrate hydrolyzing activity. Both the KPH12 and KJJ81 strains were grown on YPG medium plates supplemented with different glucose concentrations. First, we examined the production of carbohydrate hydrolyzing enzymes. $\mathrm{pH}$ had a higher influence on the production of carbohydrate hydrolyzing enzymes than glucose concentration. Starch and cellulose were hydrolyzed at high levels in non-buffered medium supplemented with a low glucose concentration. However, hydrolysis was remarkably reduced in both strains when the glucose concentration was increased, particularly to $10 \%$ glucose (Figure 4 and Supplementary Figure 2). 


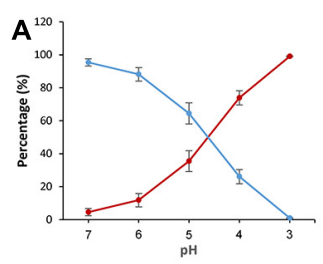

B
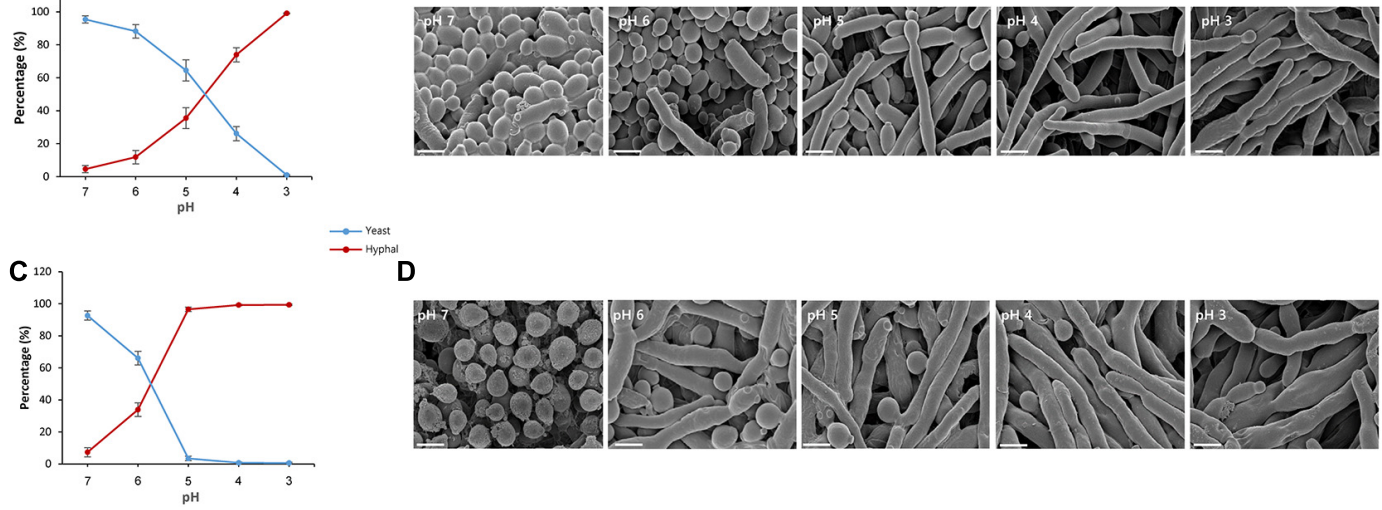

$\underset{\rightarrow-\text { Yyphal }}{\rightarrow \text { D }}$
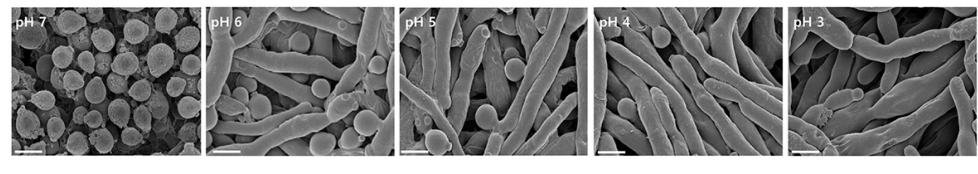

FIGURE 1 | Yeast-to-hyphae transition of Saccharomycopsis fibuligera at acidic $\mathrm{pH}$ values. KPH12 strain (A,B) and KJJ81 interspecies hybrid strain (C,D) were grown at the indicated pH values. (A,C) Percentage of yeast and mycelium in S. fibuligera grown in YPG broth buffered at pH 7, 6, 5, 4, 3 and incubated at $25^{\circ} \mathrm{C}$ for $20 \mathrm{~h}$ with shaking at $200 \mathrm{rpm}$. Blue, yeast percentage; Red, hyphae percentage. (B,D) Morphology and size of the cells at each pH value; scale bar $=4 \mu \mathrm{m}$.

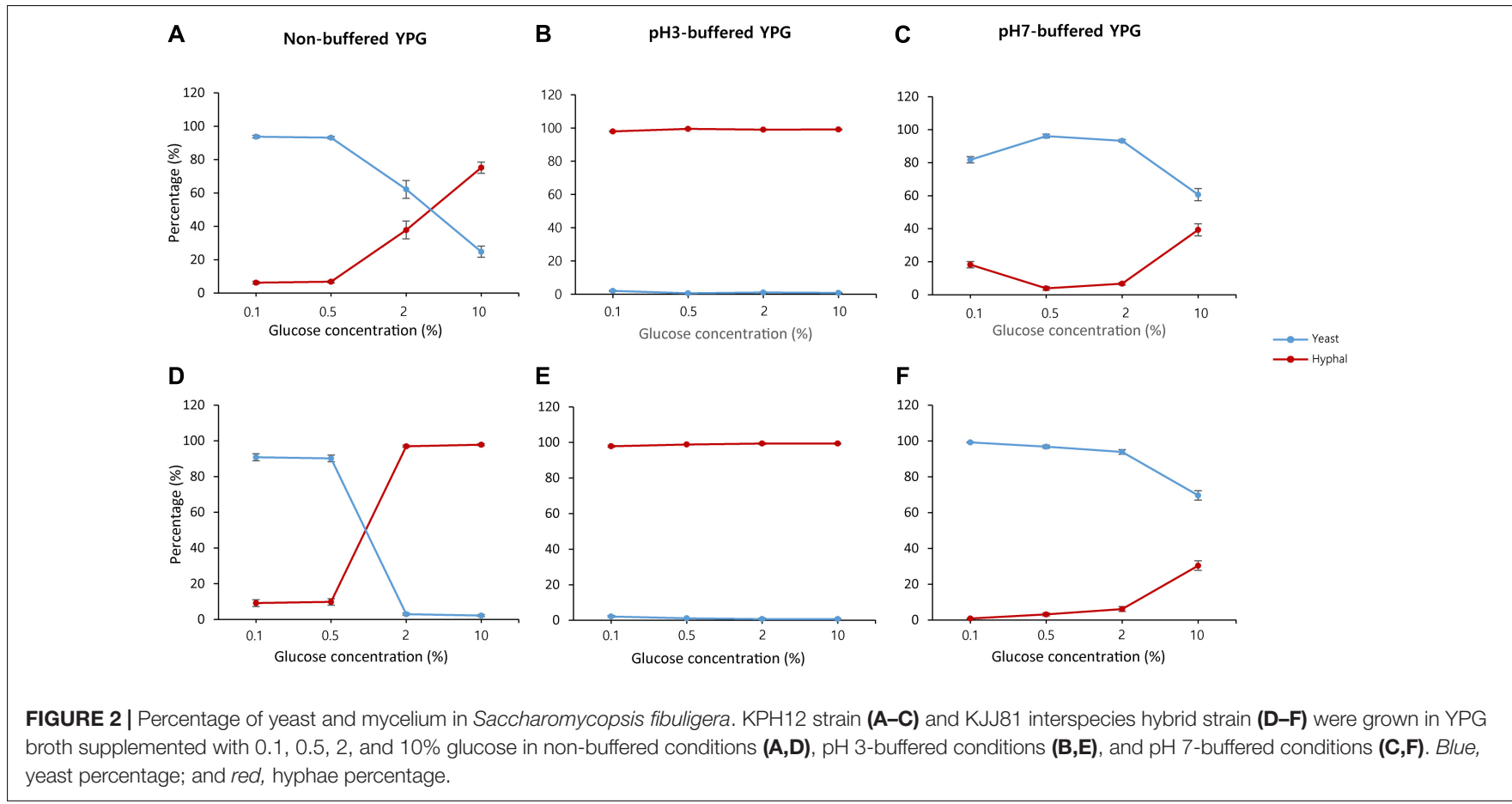

Next, we examined the effect of $\mathrm{pH}$ on the hydrolysis activity. We examined the hydrolysis activity at $\mathrm{pH} 3$ or $\mathrm{pH} 7$ and found that the hydrolysis activity of starch and cellulose was inhibited at $\mathrm{pH} 3$ and stimulated at $\mathrm{pH} 7$, regardless of the glucose concentration (Figure 4 and Supplementary Figure 2), thus indicating that $\mathrm{pH}$ has a stronger influence than glucose in determining the levels of hydrolyzing activity.

\section{pH Change Greatly Affects Gene Expression in S. fibuligera}

Based on previous results, we showed that the morphological and enzymatic alterations occurring during fermentation in
S. fibuligera are caused by the change in $\mathrm{pH}$. To investigate the effect of the changes in $\mathrm{pH}$ that occur during fermentation on the physiology of $S$. fibuligera, we analyzed the transcriptome of $S$. fibuligera at 5 different $\mathrm{pH}$ values $(\mathrm{pH} 3$ to $\mathrm{pH} 7)$. Total RNA samples were prepared from the cultures, and poly (A)-enriched RNA samples were subjected to high-throughput Illumina HiSeq 2500 sequencing. We obtained 18-40 million reads with Q30 percentages ranging from 88 to over $92 \%$. After alignment with reference genomes of $\mathrm{KPH} 12$ and $\mathrm{KJJ} 8$, the transcripts were annotated, and out of 6,231 and 12,341 genes annotated in the S. fibuligera KPH12 and KJJ81 strains, 6,075 (Supplementary Table 1) and 12,026 (Supplementary Table 2) were expressed, respectively. 

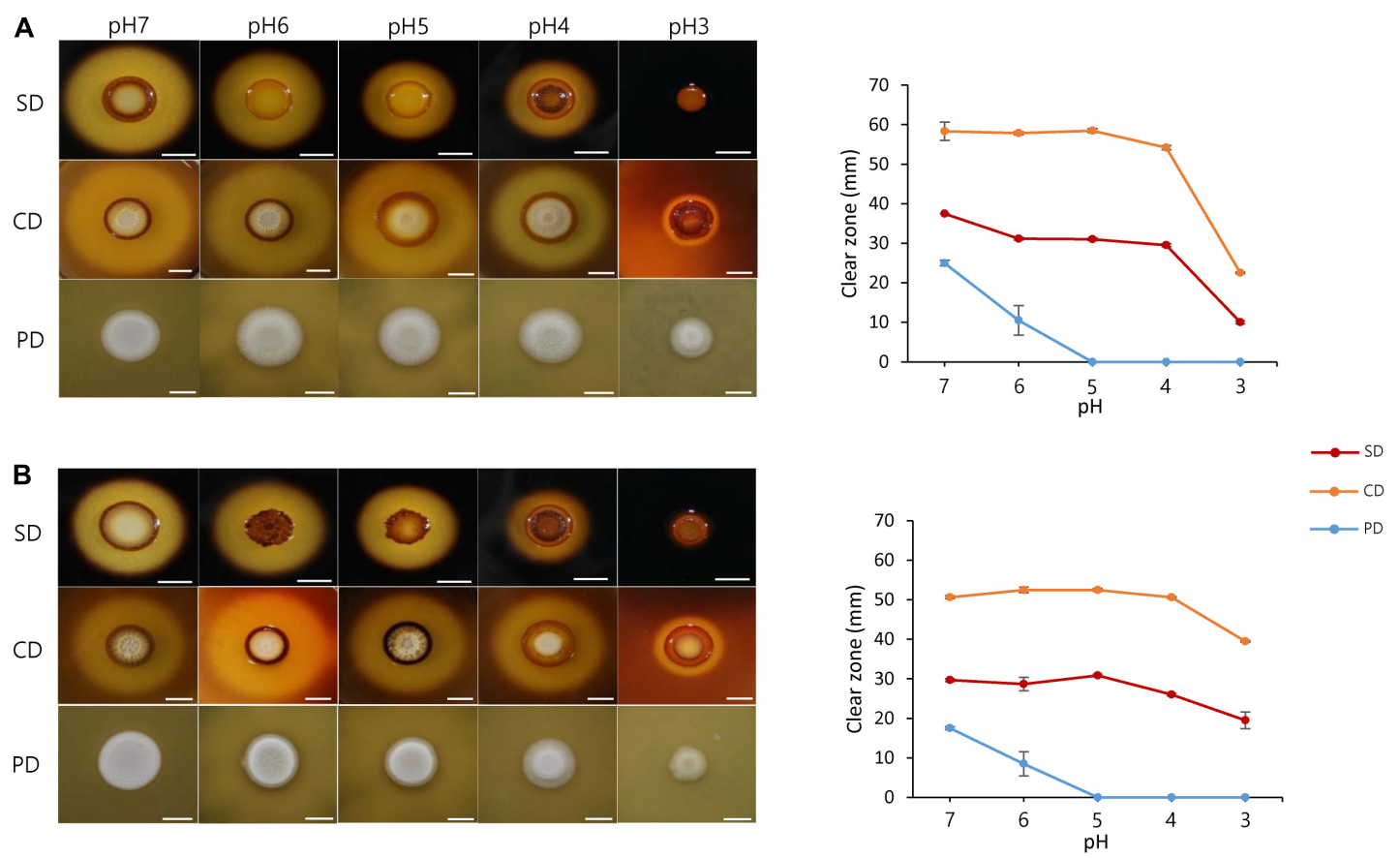

FIGURE 3 | Starch, cellulose, and protein degradation by Saccharomycopsis fibuligera. KPH12 strain (A) and KJJ81 interspecies hybrid strain (B) grown on YPG agar buffered at $\mathrm{pH} 7, \mathrm{pH} 6, \mathrm{pH} 5, \mathrm{pH} 4$, and $\mathrm{pH} 3$ at $25^{\circ} \mathrm{C}$. Degradation assays for starch, cellulose, and proteins were performed by adding $0.2 \%$ starch, $0.2 \%$ carboxymethylcellulose, and $2 \%$ skim milk. The results for starch degradation were obtained 3 days after incubation, and the results for cellulose and protein degradation were obtained 5 days after incubation. SD, starch degradation; CD, cellulose degradation; PD, protein degradation; scale bar $=10 \mathrm{~mm}$.
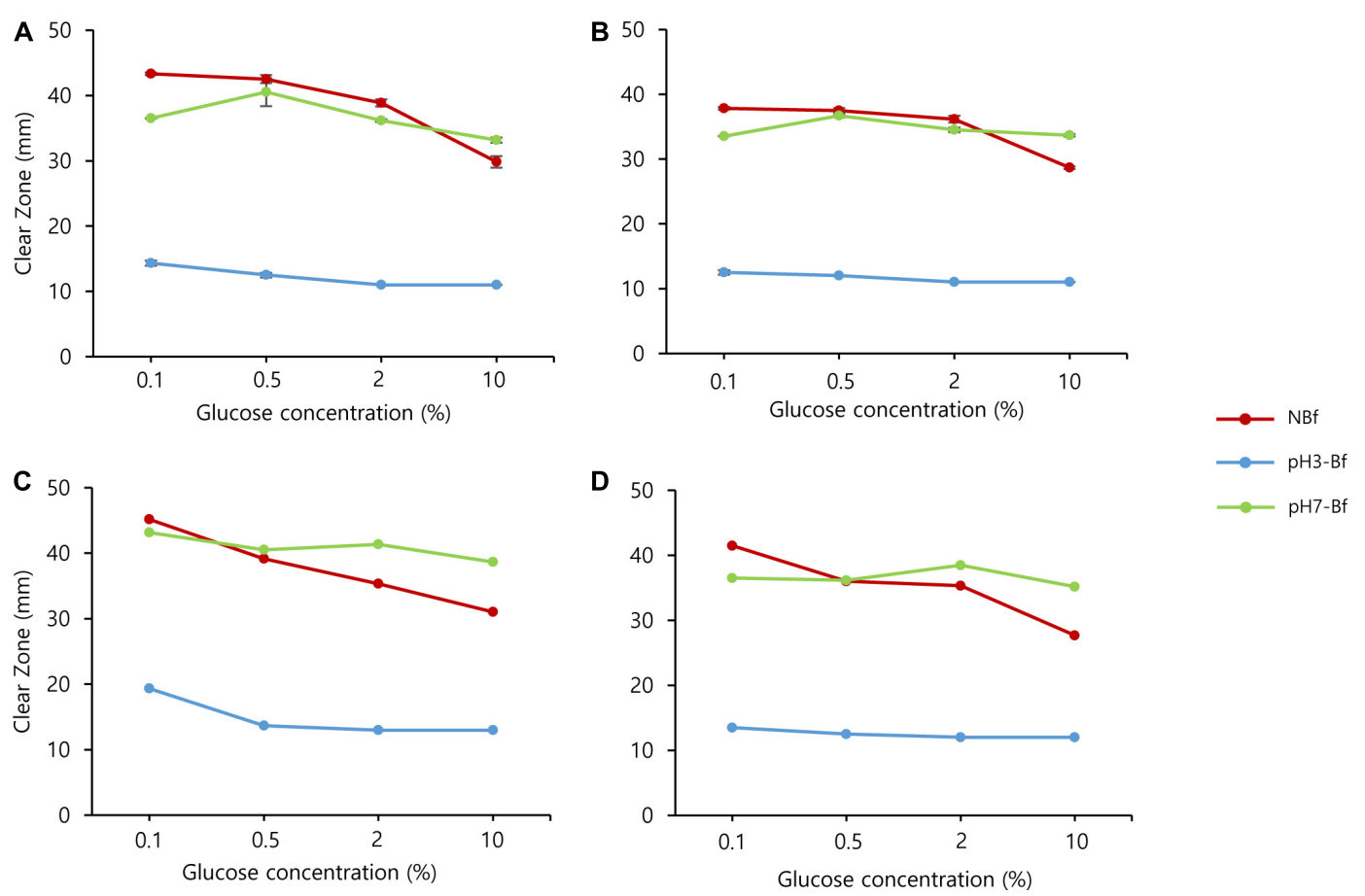

FIGURE 4 | Saccharomycopsis fibuligera shows reduced starch and cellulose degradation as $\mathrm{pH}$ decreases. Starch (A,C) and cellulose degradation (B,D) by Saccharomycopsis fibuligera. KPH12 (A,B) strain and KJJ81 interspecies hybrid strain (C,D) were grown on YPG agar plates supplemented with 0.1, 0.5, 2, and $10 \%$ glucose in non-buffered (NBf), $\mathrm{pH}$ 3-buffered (pH 3-Bf), and pH 7-buffered (pH 7-Bf) conditions. Red, non-buffered; blue, $\mathrm{pH}$ 3-buffered; and green, pH 7-buffered. 
Multidimensional scaling (MDS) analysis was performed with the RNA samples of each strain to estimate the variability among the samples. We found that the samples aggregated on the PCs based on the $\mathrm{pH}$ point. The three replicates at each $\mathrm{pH}$ point were clustered together (Figure 5). PC1 accounted for 56-61\% of the total variation among the samples, and PC2 accounted for limited variations (20-29\%). This result indicates high variation between different $\mathrm{pH}$ conditions as well as relatively low variation among replicates.

\section{Detection of Differentially Expressed Genes (DEGs)}

At the beginning and end of fermentation, the $\mathrm{pH}$ values were 7 and 3, respectively. At these two $\mathrm{pH}$ values, S. fibuligera showed the clearest difference in hydrolytic enzyme production and morphology. Thus, we determined the genes differentially expressed at the two $\mathrm{pH}$ values $(\mathrm{pH} 7$ and $\mathrm{pH}$ 3). The EdgeR package in $\mathrm{R}$ was used for differentially expressed gene (DEG) determination based on a FDR less than 0.05 . Accordingly, 3,867 out of 6,075 genes (Figure 6A and Supplementary Table 3) and 9,176 out of 12,026 genes (Figure 6B and Supplementary Table 4) were detected as DEGs in the transcriptomes of the KPH12 and KJJ81 strains, respectively. To identify the DEGs that were extremely up- and downregulated between $\mathrm{pH} 7$ and $\mathrm{pH}$ 6 , we employed fuzzy c-means clustering for all DEGs of each strain and investigated the enrichment of the biological processes (BPs) of each cluster. We grouped 3,867 DEGs and 9,176 DEGs of KPH12 and KJJ81 into five clusters (Supplementary Figure 3), respectively. For the KPH12 (Supplementary Table 5) and KJJ81 (Supplementary Table 6) strains, each cluster displayed a unique expression pattern and had significant BPs. Among them, we selected the clustered genes whose expression was highly increased and decreased between $\mathrm{pH} 7$ and $\mathrm{pH}$ 6; cluster 2 and cluster 5 of KPH12 and cluster 4 and cluster 2 of KJJ81 contained highly upregulated and highly downregulated genes, respectively (Figure 7A).

\section{Expression Pattern and Biological Processes of the Selected Clusters}

The expression patterns of cluster 5 of KPH12 and cluster 2 of KJJ81 were similar to each other and represented the DEGCs (Figure 7A). The expression of the genes in these clusters was highest at $\mathrm{pH} 7$ and then rapidly declined at $\mathrm{pH} 6$ by more than twofold. The BPs enriched in these clusters were investigated using the R package topGO, filtered and visualized using REVIGO (Supek et al., 2011). The BPs related to transporting cellular components, signaling, protein modification, and metabolism were predominant in the DEGCs of both strains (Figures 7B,C and Supplementary Figure 4A). The BP of carbohydrate metabolism was also found in these clusters, indicating that both strains share many common features in gene regulation and that carbohydrate metabolism is highly influenced by $\mathrm{pH}$. In addition, among the BPs identified by the clusters, a few differences were found between the two strains. For example, the regulation of GTPase activity was higher in KPH12 than in KJJ81.
Unlike DEGCs, the expression patterns of clusters 2 and 4, which represented the increasingly expressed gene clusters (IEGCs) of KPH12 and KJJ81, respectively, were different from each other. The expression of the genes in cluster 2 of the KPH12 strain was extremely low at $\mathrm{pH} 7$ and then increased rapidly to reach the highest level at $\mathrm{pH} 4$, whereas the expression of the genes in cluster 4 of KJJ81 was at the highest level at $\mathrm{pH}$ 4 (Figure 7A). BPs that were predominant in these clusters of both strains were related to protein synthesis and RNA metabolism. The gene number of ribosome biogenesis-related BP was higher in KJJ81 than KPH12 (Figures 7B,C, Supplementary Figure 4A, and Supplementary Tables 5,6). These results suggest that adaptation to acidic $\mathrm{pH}$ involves a change in metabolism.

The KEGG pathway enrichment analysis revealed that the DEGs were enriched in arginine biosynthesis, aminoacyltRNA biosynthesis, starch and sucrose metabolism in both strains (Supplementary Figure 4B). In strain KJJ81, the upregulated genes were clustered in the fatty acid biosynthesis and $\mathrm{N}$-glycan biosynthesis pathways and the downregulated genes were enriched in starch and sucrose metabolism. In strain $\mathrm{KPH} 12$, the upregulated genes were enriched in the lipopolysaccharide biosynthesis pathway and the downregulated genes were clustered in amino acid biosynthesis pathways (Supplementary Figure 4B).

\section{Expression of the Genes Involved in Carbohydrate Degradation}

In $S$. fibuligera, we investigated the expression of genes previously known to be involved in starch degradation, such as a-amylase (ALP1) and glucoamylases (GAM1 and $G L U$ ), and those involved in cellulose degradation, such as $\beta$-glucosidases $(B G L)$, polysaccharide monooxygenase (Cel61a) and alpha-L-arabinofuranosidase C (abfC). Most of the genes involved in starch degradation were downregulated (Figure 8A). Three of these genes, GAM1 (KPH12A7G027400, KJJ81A4G036700, KJJ81B7G026300), GLU1 (KPH12A1G148700, KJJ81A6G044500, KJJ81B1G146400) and GLU2 (KPH12A6G044000, KJJ81A6G044500, KJJ81B 6G043300), are among the DEGs of KPH12 and KJJ81. We confirmed the downregulation of most of these genes at $\mathrm{pH} 3$ by qRT-PCR (Figure 8B). All these genes were present in clusters 1 and 5 except GLU2, which was present in clusters 2 and 3 in KPH12 (Supplementary Figure 3A). On the other hand, most of these genes were present in cluster 2 of the DEGCs and in cluster 5 in both the A and B genomes of hybrid strain KJJ81 (Figure 7A). Only GAM1 was located in different clusters, and it was in cluster 5 of genome A and cluster 2 of genome B (Supplementary Figure 3A).

Among the genes related to cellulose degradation, five out of the 8 genes in genome A and 6 out of 9 in genome $\mathrm{B}$ were downregulated in the two strains (Figure 8A). All the downregulated genes of KPH12 were located in DEGs. Among them, BGL3 and Cel61a1 were in cluster 5 of the DEGCs, whereas the remaining 3 genes, BGL1 (KPH12A2G002200, KJJ81A2G002300, KJJ81B2G002200), Cel61a3 (KPH12A2G080500, KJJ81A2G080600, KJJ81B2 

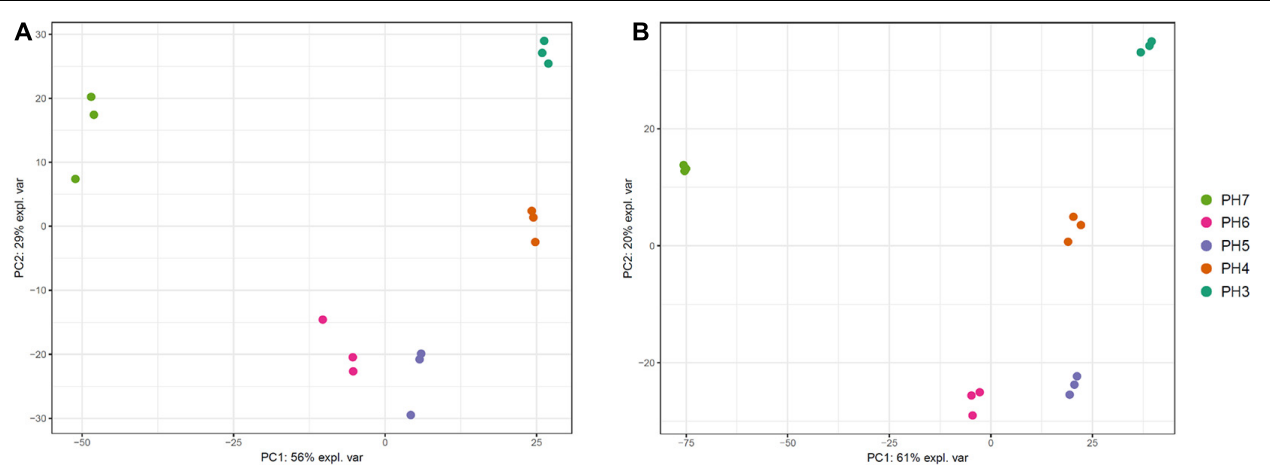

FIGURE 5 | Multidimensional scaling (MDS) plot of 15 RNA samples of Saccharomycopsis fibuligera. KPH12 strain (A) and KJJ81 interspecies hybrid strain (B) were grown at five different $\mathrm{pH}$ values for $18 \mathrm{~h}$ after inoculation, and total mRNA was prepared and sequenced. Dot colors: each dot color indicates the samples at the same $\mathrm{pH}$ point.
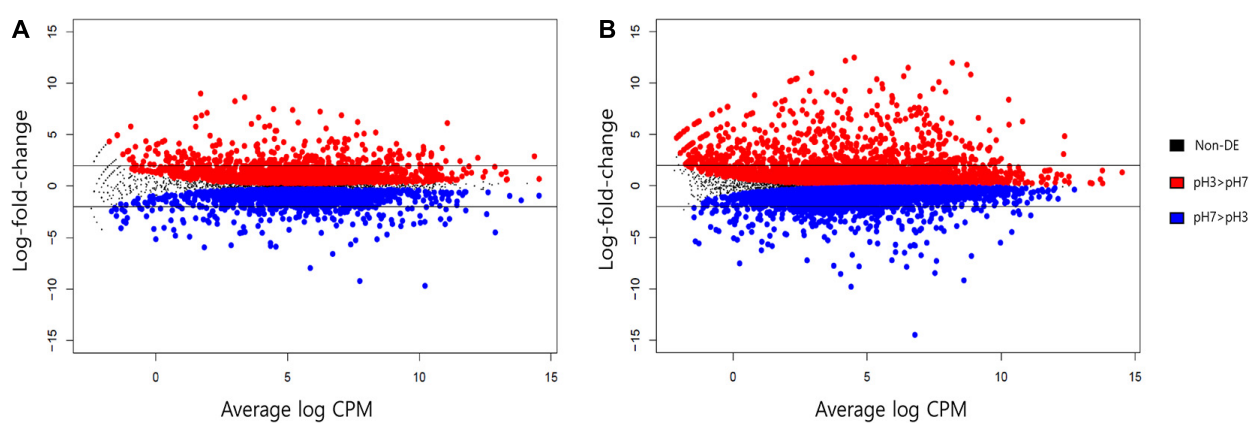

FIGURE 6 | MD plot analysis for the average expression level of all genes of Saccharomycopsis fibuligera. KPH12 strain (A) and KJJ81 interspecies hybrid strain (B) at $\mathrm{pH} 3$ and the $\log _{2}$ fold-change of each gene from $\mathrm{pH} 3$ to $\mathrm{pH} 7$. Blue: genes with a significant decrease in expression at an FDR of $5 \%$; and red: genes with a significant increase in expression at an FDR of $5 \%$. Non-significant genes are in black. Horizontal black bars indicate genes that exhibited at least a fourfold change in expression $\left(\log _{2} \mathrm{FC}=2\right)$.

G078400), and abfC (KPH12A3G089600, KJJ81A3G090700, KJJ81B5G075900), were in cluster 1 (Supplementary Figure 3A). On the other hand, these genes were downregulated in the hybrid strains and were present in the DEGs except Cel61a3 of genome B. Two of these DEGs, BGL1 and Cel61a1, were found in cluster 2, and BGL3 was in cluster 5 (Supplementary Figure 3A). $a b f C$ of genome $\mathrm{A}$ was found in cluster 2 of the DEGCs (Figure 7A), while that of genome B was not found in any cluster. The reduced expression of most of these genes was confirmed by qRT-PCR (Figure 8B). RIM101 (KPH12A2G072500, KJJ81A2G072500, KJJ81B2G070400), a $\mathrm{pH}$-response transcription factor, was associated with the expression of starch and cellulose degradation-related genes (Figure 8A). Thus, we examined its expression in both strains under different $\mathrm{pH}$ conditions. RIM101 was found in clusters 5 and 2 of the DEGCs in KPH12 and KJJ81, respectively. We confirmed the low expression of RIM101 at pH 3 by qRT-PCR, which was consistent with the RNA-Seq data (Figure 8B).

\section{Expression of the Genes Involved in the Dimorphism}

cAMP-PKA and MAPK cascades are well-known signaling pathways involved in the induction of pseudohyphal growth of the model yeast S. cerevisiae (Pan et al., 2000) and the hyphal or yeast form in other dimorphic fungal models (Leberer et al., 2001; Martínez-Espinoza et al., 2004). We examined the expression of homologous genes in S. fibuligera that are involved in these cascades, such as transcriptional activator FLO8 (KPH12A6G0101800, KJJ81A6G018300), enhanced filamentous growth EFG1 (KPH12A1G008700, KJJ81A1G009000, KJJ81B1G008600), and transcription factor TEC1 (KPH12A7G016700, KJJ81A7G016700, KJJ81B7G015800), for cAMP-PKA and transcription factor CPH1 (KPH12A3G005900, KJJ81A3G005800, KJJ81B3G006100) for MAPK. These transcriptional activators were among the DEGs except for FLO8 and TEC1. The expression of CPH1 was slightly downregulated in KPH12 and the two genomes of the hybrid strain KJJ81 (Figure 9A), and at least one of the cAMP-PKA transcriptional activators FLO8, EFG1, or TEC1 was upregulated (Figure 9A). These results suggest that the cAMPPKA pathway is involved in the hyphal growth of $S$. fibuligera. To confirm this supposition, KPH12 and KJJ81 cells were grown in YPG broth media buffered at $\mathrm{pH} 4$ in the presence or absence of clozapine, which blocks the cAMP-PKA signaling pathway (Midkiff et al., 2011), and the morphology was examined. In the liquid cultures, hyphal growth was suppressed in both strains by up to 60.4 and $26.2 \%$ for KPH12 and KJJ81, respectively, 

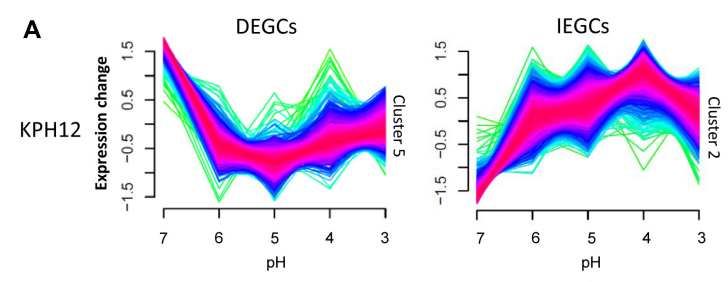

KJJ81
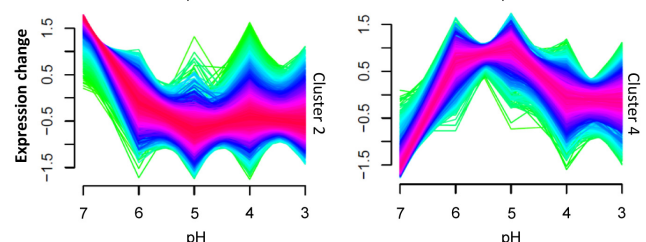

B

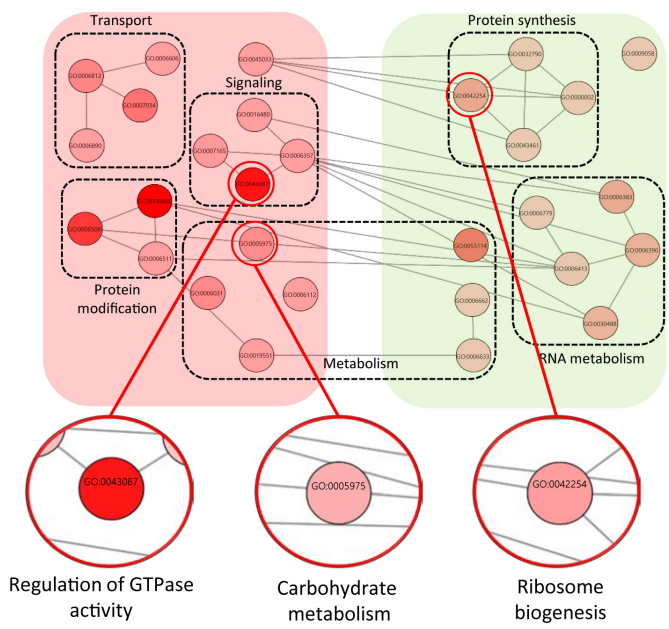

C

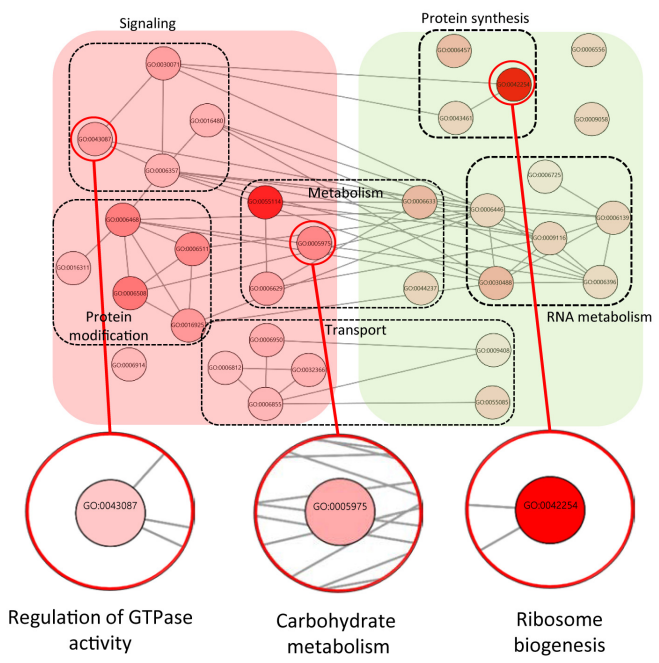

FIGURE 7 | Fuzzy c-means clustering identifies general gene expression patterns of Saccharomycopsis fibuligera. (A) Clusters of DEGCs and IEGCs of $\mathrm{KPH} 12$ and $\mathrm{KJJ} 81$ strains at $\mathrm{pH}$ values from 7 to 3 . Among the five gene clusters classified by fuzzy c-means, two clusters that showed extreme upregulation and downregulation at $\mathrm{pH} 6$ were selected. The membership of a given gene within a cluster is represented by color, with red indicating high association. (B,C) For each cluster, enriched biological processes were identified, and only those belonging to the chosen clusters were visualized based on REVIGO. Nodes represent the terms, and edges represent the strength of the terms pairwise similarity. Significance is represented by node color. DEGCs, decreasingly expressed gene clusters; IEGCs, increasingly expressed gene clusters. in the presence of clozapine (Figure 9B), indicating that the cAMP-PKA pathway plays a pivotal role in hyphal induction in both strains, KPH12 and KJJ81.

\section{DISCUSSION}

In this study, we investigated the growth of $S$. fibuligera and production of hydrolytic enzymes during fermentation. During makgeolli production, the microorganisms originating from nuruk affect the environmental conditions of fermentation and vice versa. We focused on $S$. fibuligera because this microorganism is one of the most predominant amylolytic and cellulose-degrading yeasts in nuruk (Carroll et al., 2017). We found that $S$. fibuligera undergoes several phenotypic changes, such as the dimorphic transition as the $\mathrm{pH}$ goes down. Additionally, we showed that acidic conditions ( $\mathrm{pH}$ 5-3) induce the yeast-to-hyphal transition of $S$. fibuligera, whereas neutral conditions ( $\mathrm{pH} 7$ ) induce yeast growth. Thus, the morphological change of $S$. fibuligera is consistent with the $\mathrm{pH}$ decline that is observed on the second day of makgeolli fermentation (Song et al., 2015). The morphological change of S. fibuligera was similar to that of $U$. maydis, which grows as mycelium at pH 3 and as yeast at pH 7 (Ruiz-Herrera et al., 1995), but differs from that of $Y$. lipolytica and C. ablicans, which grow as yeast at acidic $\mathrm{pH}$ and as hyphae under neutral $\mathrm{pH}$ conditions (Ruiz-Herrera and Sentandreu, 2002; Davis, 2003). Compared with the parental strains, we observed that the hybrid strain underwent hyperfilamentation, which might be another kind of adaptation to acidic pH. However, Choo and coworkers (Choo et al., 2016) found that a high concentration of glucose also induced the hyphal growth of the two strains of S. fibuligera, KPH12 and KJJ81.

The yeast to hyphal transition of $S$. fibuligera during fermentation was further examined at the level of gene expression. The expression patterns of genes involved in the dimorphic transition in S. fibuligera were investigated through transcriptome analysis. The Rim101/Pac signaling pathway plays an essential role during the dimorphic transition in response to alkaline pH (Davis, 2009). As shown in Figure 8, the RIM101 gene was upregulated at neutral $\mathrm{pH}$ and downregulated at acidic pH. Wang et al. (2020) found that in Trichosporon cutaneum, neutral and acidic $\mathrm{pH}$ induces and inhibit the expression of RIM101, respectively, which correlates with our findings. Under alkaline conditions, $C$. albicans senses $\mathrm{pH}$ signals through the membrane receptor RIM21, which activates the arresting protein RIM8. RIM8 interacts with the endosomal sorting complexes required for transport (ESCRT) complex and stimulates the expression of RIM20 (zinc finger transcription factor) and RIM13 (calpain protease) (Henne et al., 2011). RIM20 and RIM13 form a complex that hydrolyzes the long form of RIM101 into a short form (Garnaud et al., 2018). The short form of RIM101 induces the expression of $\mathrm{pH}$-responsive protein 1 $(P H R 1)$, which plays an important role in growth at alkaline $\mathrm{pH}$ (Saporito-Irwin et al., 1995), and suppresses the expression of PHR2 (pH-responsive protein 2) (Baek et al., 2006). PHR2 is induced at acidic $\mathrm{pH}$ and required for infection by C. albicans. In our study, the meiotic activator RIM4 (KPH12A1G023400) and 

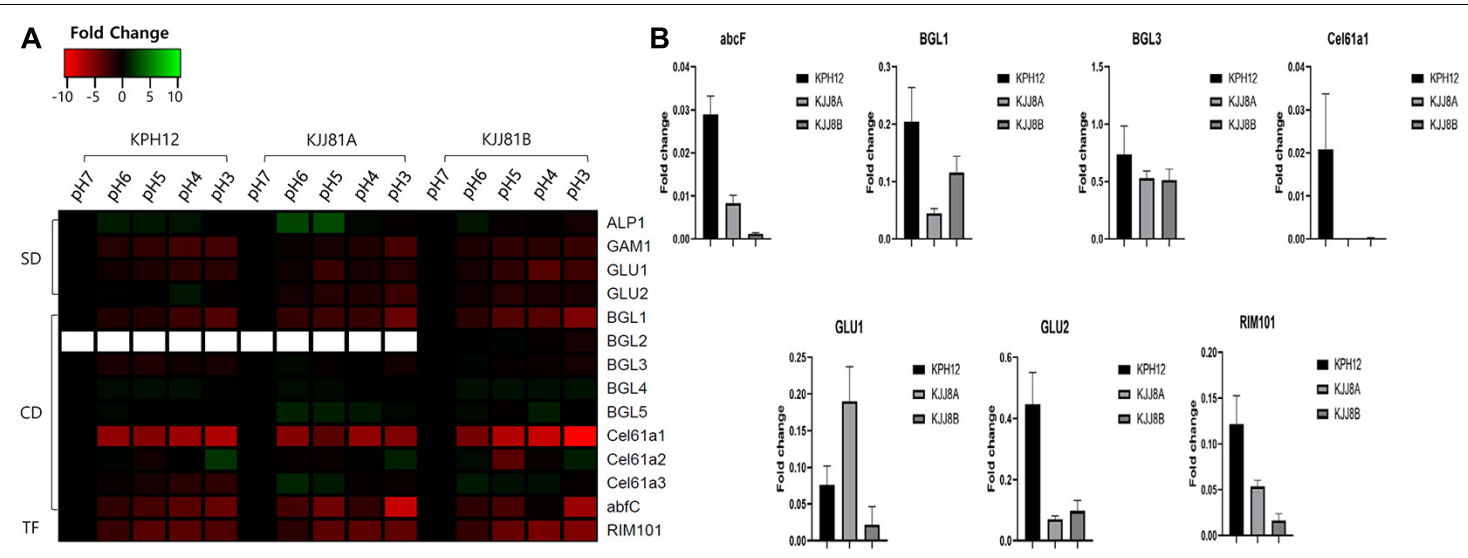

FIGURE 8 | Expression profiles of Saccharomycopsis fibuligera genes associated with starch and cellulose degradation as well as the transcription factor RIM101. (A) Genes encoding the hydrolytic enzymes were analyzed using the data from RNA-Seq for their expression at the five $\mathrm{pH}$ values and presented as a heat map. $\mathrm{pH}$ 7 was considered the starting point $\left(\log _{2} \mathrm{FC}=0\right.$ ), and the expression change at each $\mathrm{pH}$ was calculated based on pH $7 . \mathrm{SD}$, starch degradation; $\mathrm{CD}$, cellulose degradation; TF, transcription factor. (B) qRT-PCR analysis. To confirm the results obtained from the RNA-seq data, a qRT-PCR assay was performed for the indicated genes using specific primers. Error bar, standard deviation $(n=3)$.
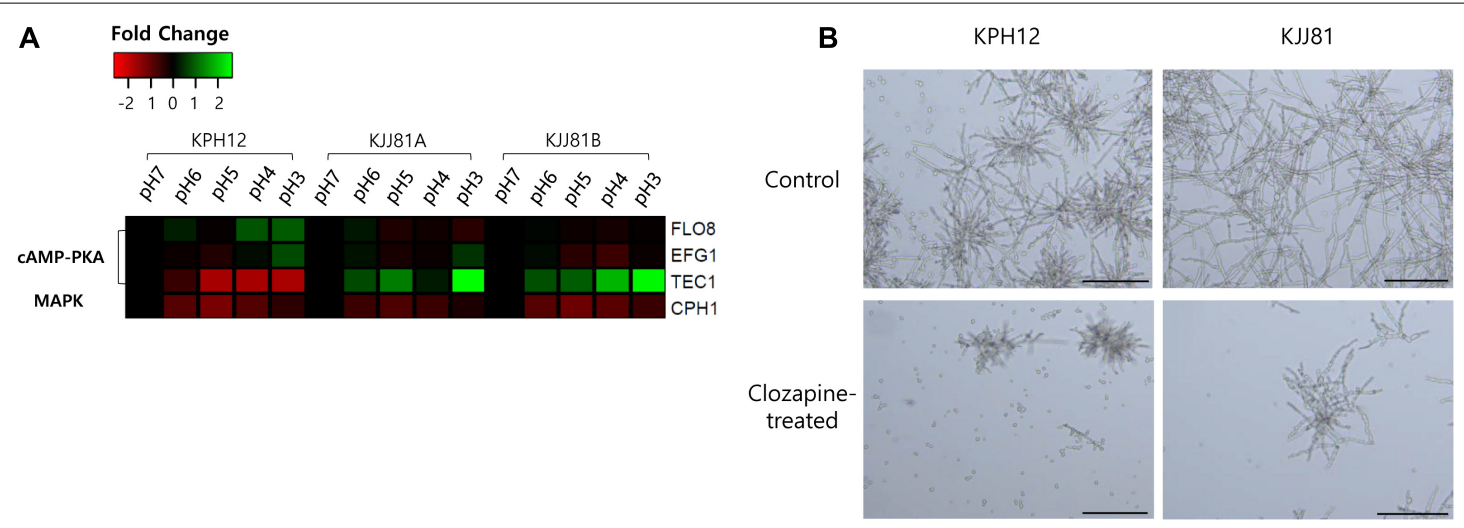

FIGURE 9 | Expression profiles of Saccharomycopsis fibuligera transcriptional activators of cAMP-PKA and MAPK, the two signaling pathways associated with the dimorphic growth of several model yeasts and fungi, at each $\mathrm{pH}$ point. $\mathrm{pH} 7$ was considered the starting point (log $2 \mathrm{FC}=0$ ), and the expression at each $\mathrm{pH}$ was calculated based on $\mathrm{pH}$ 7. (A) shows the RNA-Seq data and (B) shows the cell morphology of S. fibuligera strains in the presence or absence of the cAMP-PKA blocker clozapine. SD, starch degradation; CD, cellulose degradation; TF, transcription factor; scale bar = $100 \mu \mathrm{m}$.

pH-response regulator protein RIM20 (KPH12A4G038700) were downregulated under acidic $\mathrm{pH}$ conditions along with the key regulator RIM101 (KPH12A2G072500) in S. fibuligera KPH12 (Supplementary Table 8). In addition, the expression patterns of RIM101 (KJJ81A2G072500), RIM4 (KJJ81A1G023900) and RIM20 (KJJ81B4G038300) in the hybrid strain KJJ81 were similar to those in $S$. fibuligera KPH12. These results may indicate conservation of the RIM101 pathway in $S$. fibuligera. Furthermore, the transcriptional repressor of filamentous growth TUP1 (KPH12A4G054300), which is under the control of the RIM101 pathway, was downregulated at acidic pH (Supplementary Table 8). TUP1 forms with the general transcriptional corepressor SNN6 a complex repressor (TUP1-SSN6), which is conserved in eukaryotes. The TUP1-SSN6 complex plays a key role in growth regulation in several dimorphic fungi (Smith and Johnson, 2000) by modulating sequence-specific DNA-binding proteins (DBPs). Among the DPBs, MIG1 (regulator protein MIG1 involved in glucose repression), NRG1 (transcriptional repressor involved in regulation of glucose repression) and RFG1 (repressor of filamentous growth 1) inhibit filamentinducing genes by binding to the TUP1-SSN6 complex in C. albicans (Kebaara et al., 2008; Sánchez-Arreguin et al., 2021). Compared with the results of previous studies, the current study found that NRG1 (KPH12A4G012800, KPH12A2G036800, KJJ81A3G036900, KJJ81B3G035800) and RFG1 (KPH12A2G100300, KJJ81B2G097900) were upregulated in $S$. fibuligera under acidic $\mathrm{pH}$ conditions (Supplementary Tables 8, 9). These results suggest that NRG1 and RFG1 could play different roles during changes in environmental $\mathrm{pH}$.

In addition to transcription factors, we found that some DEGs involved in the cAMP/PKA pathway were differentially expressed (Figure 9 and Supplementary Figure 4). Cyclic AMP-protein kinase (cAMP/PKA) and MAPK are two signaling pathways 
that play a central role in the regulation of morphogenesis in several fungi, including S. cerevisiae (Conrad et al., 2014), C. albicans (Lin and Chen, 2018), and T. cutaneum (Wang et al., 2020). However, the two signaling pathways are not functionally conserved among various fungi. For instance, both signaling pathways are involved in the induction of the pseudohyphal and hyphal growth of $S$. cerevisiae and C. albicans, respectively (Sudbery, 2011), whereas in Y. lipolytica, only MAPK is involved in the induction of hyphal growth while cAMP/PKA induces yeast growth (Ruiz-Herrera and Sentandreu, 2002; CervantesChávez and Ruiz-Herrera, 2006; Martínez-Soto and RuizHerrera, 2015). In U. maydis, hyphal growth is induced only by cAMP/PKA and yeast growth is induced by MAPK (MartínezEspinoza et al., 2004). Alkaline $\mathrm{pH}$ signals induce the activation of adenylate cyclase (CYR1) and PKA through RAS2 and GPA2, which leads to the activation of transcription factors, such $R G T 1$, EFG1 and TEC1, in C. albicans (Zhang et al., 2016). These transcription factors play a key role in hyphal growth, and their activation leads to translation from yeast to hyphal form (Han et al., 2011; Cornet and Gaillardin, 2014). In this study, the expression of G-protein alpha-subunit (GPA2, KJJ81B5G067700), Ras-like protein 1 (RAS1, KJJ81B2G095300), and G proteincoupled receptor 1 (GPR1, KJJ81B4G062500) involved in the CAMP/PKA pathway was upregulated at acidic $\mathrm{pH}$ in hybrid strain KJJ81 (Supplementary Table 9). Furthermore, the transcription factors TEC1 (KJJ81A7G016700, KJJ81B7G015800) and EFG1 (KPH12A1G008700) were upregulated under acidic conditions (Supplementary Tables 8, 9), which is consistent with previous studies in T. cutaneum (Wang et al., 2020). Thus, these results suggest that the cAMP/PKA pathway is involved in the regulation of hyphal growth at acidic $\mathrm{pH}$ in the hybrid strain S. fibuligera KJJ81 (Figure 9 and Supplementary Table 9).

During fermentation, the most crucial process is the degradation of carbohydrates in nuruk to produce substrates of alcohol. Thus, the production of hydrolyzing enzymes should be crucial for successful fermentation. However, as fermentation progresses, the $\mathrm{pH}$ drops, which in turn leads to a decrease in the production of hydrolytic enzymes for starch, cellulose and proteins in S. fibuligera (Figure 3), and these conditions are not favorable for fermentation. In addition, a high concentration of glucose suppresses the production of hydrolytic enzymes for starch, protein, and cellulose in S. fibuligera (Chi et al., 2009). Choo et al. (2016) showed that the reduced production of these enzymes under high concentrations of glucose is caused by the downregulation of the genes encoding hydrolytic enzymes. A previous study showed that a high concentration of glucose changed the environmental $\mathrm{pH}$ to alkaline conditions in C. albicans (Carman, 2008). Thus, it is not clear whether a high glucose concentration directly affects the production of hydrolytic enzymes. However, in this work, we showed that the $\mathrm{pH}$ change resulting from glucose utilization but not glucose itself plays a critical role in the dimorphic transition and the reduced production of hydrolytic enzymes in $S$. fibuligera (Supplementary Figure 2). The transcriptome analysis revealed that genes encoding enzymes involved in starch, cellulose and protein degradation were downregulated at acidic $\mathrm{pH}$ (Figure 8). ALP1 (KPH12A6G028500, KJJ81A6G028500, KJJ81B6G028100), GAM1 (KPH12A7G02 7400, KJJ81A7G027600, KJJ81B7G026300), GLU1 (KPH1 2A1G148700, KJJ81A1G148800, KJJ81B1G146400) and GLU2 (KPH12A6G044000, KJJ81A6G044500, KJJ81B6G043300), which encode enzymes involved in starch degradation, were downregulated at acidic $\mathrm{pH}$ compared to alkaline $\mathrm{pH}$ (Supplementary Tables 8, 9). In addition, the expression of RIM101 was decreased at acidic $\mathrm{pH}$. In the model filamentous organism Aspergillus nidulans, the deletion of RIM101 resulted in a lower expression of carbohydrate degradation-related genes (Peñalva et al., 2008). Thus, it is possible that RIM101 could be involved in the regulation of carbohydrate degradation-related genes in S. fibuligera.

We investigated the expression of genes involved in protein synthesis and RNA metabolism. Through an analysis of BPs, the genes linked to RNA metabolism and protein synthesis, such as CTK2 (CTD kinase subunit beta, KPH12A5G020700, KJJ81B5G020000), DBP3 (ATP-dependent RNA helicase DBP3, KPH12A7G005900, KJJ81A7G005800, KJJ81B7G005500) and CBP6 (KPH12A2G119900, KJJ81A2G119600, KJJ81B2G116300), were upregulated under hyphal induction conditions (Supplementary Tables 8, 9). A transcriptome analysis of C. albicans under the condition of transition from yeast to hyphae showed an upregulation of genes involved in RNA metabolism and protein synthesis (Carlisle and Kadosh, 2013). Similar results were observed with $U$. maydis during the transition from yeast to hyphal forms (Larraya et al., 2005). However, contrasting cases are observed as well, and genes linked with protein synthesis and RNA metabolism were involved in the transition to the yeast form in Paracoccidioides brasiliensis (Nunes et al., 2005; Parente et al., 2008), Penicillium marneffei (a human pathogen) (Yang et al., 2014) and Ophiostoma novoulmi (a plant pathogen) (Nigg and Bernier, 2016). C. albicans and $U$. maydis exist in yeast form as saprotrophs in the environment (Vollmeister et al., 2011; Carlisle and Kadosh, 2013; Ruiz-Herrera et al., 2020), and they turn into filamentous forms to infect their hosts. In contrast, the opposite is true for P. brasiliensis, P. marneffei and O. novo-ulmi (Rooney and Klein, 2002; Naruzawa and Bernier, 2014). Therefore, the high-level expression of genes involved in protein synthesis and RNA metabolism may not be a direct indicator of the transition from yeast to hyphae but rather an indication of adaptation to changing environmental conditions. Accordingly, the transition of $S$. fibuligera from yeast to hyphae is an adaptation to acidic $\mathrm{pH}$ supported by the high-level expression of genes related to protein synthesis and RNA metabolism. In addition, cell wall synthesis is tightly regulated under hyphal formation conditions. $B C R 1$ (biofilm and cell wall regulator 1) is a transcription factor that plays a key role in the regulation of cell wall formation and regulates the expression of genes involved in cell wall synthesis (HWP1, ALS1, ALS3, and HYR1) (Nobile et al., 2006; Sosinska et al., 2011). The deletion of BCR1 in C. albicans induced a decrease in the expression of the cell wall chitinase Cht2 (Sherrington et al., 2017). Under acidic conditions, the S. fibuligera hybrid strain KJJ81 showed an upregulation of BCR1 
(Supplementary Table 9, KJJ81B4G072900), indicating that the function of $B C R 1$ is conserved and may play an important role in yeast-hyphal transition through regulation of cell wall synthesis and regulation of the wall proteome during adaptation.

\section{CONCLUSION}

In conclusion, the study provides evidence that the acidic $\mathrm{pH}$ conditions that occur during fermentation of nuruk underlie the phenotypes of S. fibuligera, such as the lower-level starch and cellulose degradation and hyphal growth. Here, we also provide the first detailed analysis of transcriptome changes in S. fibuligera upon $\mathrm{pH}$ decline. During the first phase of fermentation of nuruk, S. fibuligera contributes to the degradation of starch through secretion of carbohydrate-hydrolyzing enzymes. As fermentation progresses, the environmental $\mathrm{pH}$ drops to an acidic level $(\mathrm{pH}$ 3). Under these conditions, S. fibuligera undergoes a morphological transition to give rise to the hyphal form and metabolic modifications, such as inhibition of carbohydrate metabolism, to survive under acidic $\mathrm{pH}$ conditions as a means of adapting to fermentation environments. In addition, our transcriptome analysis contributes to elucidating some aspects of the dimorphism transition of S. fibuligera under low $\mathrm{pH}$ conditions that occur when fermenting makgeolli using nuruk.

\section{DATA AVAILABILITY STATEMENT}

The datasets presented in this study can be found in online repositories. The names of the repository/repositories and accession number(s) can be found below: https://www.ncbi.nlm. nih.gov/, PRJNA705233.

\section{REFERENCES}

Abouzied, M. M., and Reddy, C. A. (1987). Fermentation of starch to ethanol by a complementary mixture of an amylolytic yeast and Saccharomyces cerevisiae. Biotechnol. Lett. 9, 59-62. doi: 10.1007/bf01043395

Anders, S., Pyl, P. T., and Huber, W. (2015). HTSeq-a Python framework to work with high-throughput sequencing data. Bioinformatics 31, 166-169. doi: 10.1093/bioinformatics/btu638

Baek, Y. U., Martin, S. J., and Davis, D. A. (2006). Evidence for novel pH-dependent regulation of Candida albicans Rim101, a direct transcriptional repressor of the cell wall beta-glycosidase Phr2. Eukaryot. Cell 5, 1550-1559. doi: 10.1128/EC. 00088-06

Bal, J., Yun, S. H., Choi, M. S., Yeo, S. H., Kim, J. M., and Kim, D. H. (2015). Pyrosequencing reveals bacterial diversity in Korean traditional wheat-based nuruk. J. Microbiol. 53, 812-819. doi: 10.1007/s12275-015-5516-3

Bal, J., Yun, S. H., Song, H. Y., Yeo, S. H., Kim, J. H., Kim, J. M., et al. (2014). Mycoflora dynamics analysis of Korean traditional wheat-based nuruk. J. Microbiol. 52, 1025-1029. doi: 10.1007/s12275-014-4620-0

Benjamini, Y., and Hochberg, Y. (1995). Controlling the false discovery rate: a practical and powerful approach to multiple testing. J. R. Stat. Soc. B (Methodol.) 57, 289-300. doi: 10.1111/j.2517-6161.1995.tb02 031.x

Carlisle, P. L., and Kadosh, D. (2013). A genome-wide transcriptional analysis of morphology determination in Candida albicans. Mol. Biol. Cell 24, 246-260. doi: 10.1091/mbc.E12-01-0065

Carman, A. J. (2008). Acetate Metabolism and the Control of Environmental pH in Candida Albicans and Saccharomyces cerevisiae. Ph.D dissertation. Houston,

\section{AUTHOR CONTRIBUTIONS}

J-AS conceived the conceptualization, funding acquisition, project administration, supervision, writing the original draft, responding to revision, and editing the whole manuscript. MF performed the experiment and the RNA-sequence analysis, and drafted the first manuscript. NA participated in the RNA-seq analysis and drafted the manuscript. All authors contributed to the article and approved the submitted version.

\section{FUNDING}

This work was supported by the Korea Institute of Planning and Evaluation for Technology in Food, Agriculture and Forestry (IPET) through Agricultural Microbiome R\&D Program, funded by the Ministry of Agriculture, Food and Rural Affairs (MAFRA918010-4).

\section{ACKNOWLEDGMENTS}

We thank I. H. Hwang and Y. W. Lee for their valuable comments and discussions. We thank Ghazal Ayoub for providing the algorism used for extracting the DEGs list.

\section{SUPPLEMENTARY MATERIAL}

The Supplementary Material for this article can be found online at: https://www.frontiersin.org/articles/10.3389/fmicb. 2021.672661/full\#supplementary-material

TX: The University of Texas Graduate School of Biomedical Sciences at Houston.

Carroll, E., Trinh, T. N., Son, H., Lee, Y.-W., and Seo, J.-A. (2017). Comprehensive analysis of fungal diversity and enzyme activity in nuruk, a Korean fermenting starter, for acquiring useful fungi. J. Microbiol. 55, 357-365.

Cervantes-Chávez, J. A., and Ruiz-Herrera, J. (2006). STE11disruption reveals the central role of a MAPK pathway in dimorphism and mating in Yarrowia lipolytica. FEMS Yeast Res. 6, 801-815. doi: 10.1111/j.1567-1364.2006.00084.x

Chi, Z., Chi, Z., Liu, G., Wang, F., Ju, L., and Zhang, T. (2009). Saccharomycopsis fibuligera and its applications in biotechnology. Biotechnol. Adv. 27, 423-431. doi: 10.1016/j.biotechadv.2009.03.003

Choo, J. H., Hong, C. P., Lim, J. Y., Seo, J. A., Kim, Y. S., Lee, D. W., et al. (2016). Whole-genome de novo sequencing, combined with RNA-Seq analysis, reveals unique genome and physiological features of the amylolytic yeast Saccharomycopsis fibuligera and its interspecies hybrid. Biotechnol. Biofuels 9:246. doi: 10.1186/s13068-016-0653-4

Conrad, M., Schothorst, J., Kankipati, H. N., Van Zeebroeck, G., Rubio-Texeira, M., and Thevelein, J. M. (2014). Nutrient sensing and signaling in the yeast Saccharomyces cerevisiae. FEMS Microbiol. Rev. 38, 254-299. doi: 10.1111/15746976.12065

Cornet, M., and Gaillardin, C. (2014). pH signaling in human fungal pathogens: a new target for antifungal strategies. Eukaryot. Cell 13, 342-352. doi: 10.1128/ EC.00313-13

Cotton, P., Kasza, Z., Bruel, C., Rascle, C., and Fèvre, M. (2003). Ambient pH controls the expression of endopolygalacturonase genes in the necrotrophic fungus Sclerotinia sclerotiorum. FEMS Microbiol. Lett. 227, 163-169. doi: 10. 1016/s0378-1097(03)00582-2 
Davis, D. (2003). Adaptation to environmental $\mathrm{pH}$ in Candida albicans and its relation to pathogenesis. Curr. Genet. 44, 1-7. doi: 10.1007/s00294-003-0 431-2

Davis, D. A. (2009). How human pathogenic fungi sense and adapt to $\mathrm{pH}$ : the link to virulence. Curr. Opin. Microbiol. 12, 365-370. doi: 10.1016/j.mib.2009.05.006

de Mot, R., Andries, K., and Verachtert, H. (1984). Comparative study of starch degradation and amylase production by Ascomycetous yeast species. Syst. Appl. Microbiol. 5, 106-118. doi: 10.1016/s0723-2020(84)80055-7

Farh, M. E. A., Cho, Y., Lim, J. Y., and Seo, J. A. (2017). A diversity study of Saccharomycopsis fibuligera in rice wine starter nuruk, reveals the evolutionary process associated with its interspecies hybrid. J. Microbiol. 55, 337-343. doi: 10.1007/s12275-017-7115-y

Garnaud, C., García-Oliver, E., Wang, Y., Maubon, D., Bailly, S., Despinasse, Q., et al. (2018). The rim pathway mediates antifungal tolerance in Candida albicans through newly identified Rim101 transcriptional targets, including Hsp90 and Ipt1. Antimicrob. Agents Chemother. 62:e1785-17. doi: 10.1128/ AAC.01785-17

Gonzalez-Lopez, C. I., Szabo, R., Blanchin-Roland, S., and Gaillardin, C. (2002). Genetic control of extracellular protease synthesis in the yeast Yarrowia lipolytica. Genetics 160, 417-427.

Han, T. L., Cannon, R. D., and Villas-Bôas, S. G. (2011). The metabolic basis of Candida albicans morphogenesis and quorum sensing. Fungal Genet. Biol. 48, 747-763. doi: 10.1016/j.fgb.2011.04.002

Henne, W. M., Buchkovich, N. J., and Emr, S. D. (2011). The ESCRT pathway. Dev. Cell 21, 77-91. doi: 10.1016/j.devcel.2011.05.015

Jang, J. (1989). History of Korean traditional rice wine. Korean Diet. Cult. 4, 271-274.

Jo, G., and Lee, C. (1997). Isolation and identification of the fungi from nuruk. J. Korean. Soc. Food. Sci. Nutr. 26, 759-766.

Kebaara, B. W., Langford, M. L., Navarathna, D. H. M. L. P., Dumitru, R., Nickerson, K. W., and Atkin, A. L. (2008). Candida albicans Tup1 is involved in farnesol-mediated inhibition of filamentous-growth induction. Eukaryot. Cell 7, 980-987. doi: 10.1128/EC.00357-07

Kim, M. S., Kim, S., Ha, B. S., Park, H. Y., Baek, S. Y., Yeo, S. H., et al. (2014). Diversity, saccharification capacity, and toxigenicity analyses of fungal isolates in Nuruk. Korean J. Mycol. 42, 191-200. doi: 10.4489/kjm.2014.42.3.191

Kozubowski, L., Lee, S. C., and Heitman, J. (2009). Signalling pathways in the pathogenesis of Cryptococcus. Cell. Microbiol. 11, 370-380. doi: 10.1111/j.14625822.2008.01273.x

Kurtzman, C. P., and Smith, M. T. (2011). Saccharomycopsis Schiönning (1903). Amsterdam: Elsevier Science BV.

Larkin, M. A., Blackshields, G., Brown, N. P., Chenna, R., McGettigan, P. A., McWilliam, H., et al. (2007). Clustal W and Clustal X version 2.0. Bioinformatics 23, 2947-2948. doi: 10.1093/bioinformatics/btm404

Larraya, L. M., Boyce, K. J., So, A., Steen, B. R., Jones, S., Marra, M., et al. (2005). Serial analysis of gene expression reveals conserved links between protein kinase A, ribosome biogenesis, and phosphate metabolism in Ustilago maydis. Eukaryot. Cell 4, 2029-2043. doi: 10.1128/EC.4.12.2029-2043.2005

Leberer, E., Harcus, D., Dignard, D., Johnson, L., Ushinsky, S., Thomas, D. Y., et al. (2001). Ras links cellular morphogenesis to virulence by regulation of the MAP kinase and cAMP signalling pathways in the pathogenic fungus Candida albicans. Mol. Microbiol. 42, 673-687. doi: 10.1046/j.1365-2958.2001.02672.x

Lee, J. E., Lee, A. R., Kim, H., Lee, E., Kim, T. W., Shin, W. C., et al. (2017). Restoration of traditional Korean Nuruk and analysis of the brewing characteristics. J. Microbiol. Biotechnol. 27, 896-908. doi: 10.4014/jmb.1610. 10039

Li, H., and Durbin, R. (2009). Fast and accurate short read alignment with BurrowsWheeler transform. Bioinformatics 25, 1754-1760. doi: 10.1093/bioinformatics/ btp324

Lin, C. J., and Chen, Y. L. (2018). Conserved and divergent functions of the cAMP/PKA signaling pathway in Candida albicans and Candida tropicalis. J. Fungi 4:68. doi: 10.3390/jof4020068

Liu, L., Feizi, A., Österlund, T., Hjort, C., and Nielsen, J. (2014). Genome-scale analysis of the high-efficient protein secretion system of Aspergillus oryzae. BMC Syst. Biol. 8:73. doi: 10.1186/1752-0509-8-73

Ma, Y., Liu, X., Yin, Y., Zou, C., Wang, W., Zou, S., et al. (2015). Expression optimization and biochemical properties of two glycosyl hydrolase family 3 beta-glucosidases. J. Biotechnol. 206, 79-88. doi: 10.1016/j.jbiotec.2015.04.016
Mardis, E. R. (2008). Next-generation DNA sequencing methods. Annu. Rev. Genom. Hum. Genet. 9, 387-402. doi: 10.1146/annurev.genom.9.081307. 164359

Martínez-Espinoza, A. D., Ruiz-Herrera, J., León-Ramírez, C. G., and Gold, S. E. (2004). MAP kinase and cAMP signaling pathways modulate the $\mathrm{pH}$-induced yeast-to-mycelium dimorphic transition in the corn smut fungus Ustilago maydis. Curr. Microbiol. 49, 274-281. doi: 10.1007/s00284-004-4315-6

Martínez-Soto, D., and Ruiz-Herrera, J. (2015). Regulation of the expression of the whole genome of Ustilago maydis by a MAPK pathway. Arch. Microbiol 197, 575-588. doi: 10.1007/s00203-015-1087-2

Midkiff, J., Borochoff-Porte, N., White, D., and Johnson, D. I. (2011). Small molecule inhibitors of the Candida albicans budded-to-hyphal transition act through multiple signaling pathways. PLoS One 6:e25395. doi: 10.1371/journal. pone.0025395

Naruzawa, E. S., and Bernier, L. (2014). Control of yeast-mycelium dimorphism in vitro in Dutch elm disease fungi by manipulation of specific external stimuli. Fungal Biol. 118, 872-884. doi: 10.1016/j.funbio.2014.07.006

Nigg, M., and Bernier, L. (2016). From yeast to hypha: defining transcriptomic signatures of the morphological switch in the dimorphic fungal pathogen Ophiostoma novo-ulmi. BMC Genom. 17:920. doi: 10.1186/s12864-016-3251-8

Nobile, C. J., Andes, D. R., Nett, J. E., Smith, F. J., Yue, F., Phan, Q. T., et al. (2006). Critical role of Bcrl-dependent adhesins in C. albicans biofilm formation in vitro and in vivo. PLoS Pathog. 2:e63. doi: 10.1371/journal.ppat.0020063

Norihiro, T., Makoto, F., Hiroki, N., Norie, K., Akio, T., and Shigezo, U. (1989). Isolation of a cDNA encoding Aspergillus oryzae Taka-amylase A: evidence for multiple related genes. Gene 84, 319-327. doi: 10.1016/0378-1119(89)90506-4

Nunes, L. R., Costa de Oliveira, R., Leite, D. B., da Silva, V. S., dos Reis Marques, E., da Silva Ferreira, M. E., et al. (2005). Transcriptome analysis of Paracoccidioides brasiliensis cells undergoing mycelium-to-yeast transition. Eukaryot. Cell 4, 2115-2128. doi: 10.1128/EC.4.12.2115-2128.2005

O'Meara, T. R., and Alspaugh, J. A. (2012). The Cryptococcus neoformans capsule: a sword and a shield. Clin. Microbiol. Rev. 25, 387-408. doi: 10.1128/CMR 00001-12

Pan, X., Harashima, T., and Heitman, J. (2000). Signal transduction cascades regulating pseudohyphal differentiation of Saccharomyces cerevisiae. Curr. Opin. Microbiol. 3, 567-572. doi: 10.1016/s1369-5274(00)00142-9

Parente, J. A., Borges, C. L., Bailão, A. M., Felipe, M. S. S., Pereira, M., and de Almeida Soares, C. M. (2008). Comparison of transcription of multiple genes during mycelia transition to yeast cells of Paracoccidioides brasiliensis reveals insights to fungal differentiation and pathogenesis. Mycopathologia 165, 259-273. doi: 10.1007/s11046-007-9078-8

Park, J. S., Song, S. H., Choi, J. B., Kim, Y. S., Kwon, S. H., and Park, Y. S. (2014). Physicochemical properties of Korean rice wine (Makgeolli) fermented using yeasts isolated from Korean traditional nuruk, a starter culture. Food Sci. Biotechnol. 23, 1577-1585. doi: 10.1007/s10068-014-0214-1

Park, K. H., Liu, Z., Park, C. S., and Ni, L. (2016). Microbiota associated with the starter cultures and brewing process of traditional Hong Qu glutinous rice wine. Food Sci. Biotechnol. 25, 649-658. doi: 10.1007/s10068-016-0115-6

Peñalva, M. A., Tilburn, J., Bignell, E., and Arst, H. N. (2008). Ambient pH gene regulation in fungi: making connections. Trends Microbiol. 16, 291-300. doi: 10.1016/j.tim.2008.03.006

Reddy, O. V. S., and Basappa, S. C. (1996). Direct fermentation of cassava starch to ethanol by mixed cultures of Endomycopsis fibuligera and Zymomonas mobilis: synergism and limitations. Biotechnol. Lett. 18, 1315-1318. doi: 10. 1007/bf00129962

Robinson, M. D., McCarthy, D. J., and Smyth, G. K. (2010). edgeR: a Bioconductor package for differential expression analysis of digital gene expression data. Bioinformatics 26, 139-140. doi: 10.1093/bioinformatics/btp616

Rohart, F., Gautier, B., Singh, A., and Lê Cao, K. A. (2017). mixOmics: an R package for 'omics feature selection and multiple data integration. PLoS Comput. Biol. 13:e1005752. doi: 10.1371/journal.pcbi.1005752

Rooney, P. J., and Klein, B. S. (2002). Linking fungal morphogenesis with virulence. Cell. Microbiol. 4, 127-137. doi: 10.1046/j.1462-5822.2002.00179.x

Ruiz-Herrera, J., Leon, C. G., Guevara-Olvera, L., and Carabez-Trejo, A. (1995). Yeast-mycelial dimorphism of haploid and diploid strains of Ustilago maydis. Microbiology 141, 695-703. doi: 10.1099/13500872-141-3-695

Ruiz-Herrera, J., Pérez-Rodríguez, F., and Velez-Haro, J. (2020). The signaling mechanisms involved in the dimorphic phenomenon of the Basidiomycota 
fungus Ustilago maydis. Int. Microbiol. 23, 121-126. doi: 10.1007/s10123-01900100-5

Ruiz-Herrera, J., and Sentandreu, R. (2002). Different effectors of dimorphism in Yarrowia lipolytica. Arch. Microbiol. 178, 477-483. doi: 10.1007/s00203-0020478-3

Sánchez-Arreguin, J. A., Ruiz-Herrera, J., Mares-Rodriguez, FdJ, León-Ramírez, C. G., Sánchez-Segura, L., Zapata-Morín, P. A., et al. (2021). Acid pH strategy adaptation through NRG1 in Ustilago maydis. J. Fungi. 7:91. doi: 10.3390/ jof7020091

Saporito-Irwin, S. M., Birse, C. E., Sypherd, P. S., and Fonzi, W. A. (1995). PHR1, a pH-regulated gene of Candida albicans, is required for morphogenesis. Mol. Cell. Biol. 15, 601-613. doi: 10.1128/mcb.15.2.601

Seo, D. H., Jung, J. H., Kim, H. Y., Kim, Y. R., Ha, S. J., Kim, Y. C., et al. (2007). Identification of lactic acid bacteria involved in traditional Korean rice wine fermentation. Food Sci. Biotechnol. 16, 994-998.

Sherrington, S. L., Sorsby, E., Mahtey, N., Kumwenda, P., Lenardon, M. D., Brown, I., et al. (2017). Adaptation of Candida albicans to environmental $\mathrm{pH}$ induces cell wall remodelling and enhances innate immune recognition. PLoS Pathog. 13:e1006403. doi: 10.1371/journal.ppat.1006403

Shin, H. M., Lim, J. W., Shin, C. G., and Shin, C. S. (2017). Comparative characteristics of rice wine fermentations using Monascus koji and rice nuruk. Food Sci. Biotechnol. 26, 1349-1355. doi: 10.1007/s10068-017-0187-y

Smith, R. L., and Johnson, A. D. (2000). Turning genes off by Ssn6-Tup1: a conserved system of transcriptional repression in eukaryotes. Trends Biochem. Sci. 25, 325-330. doi: 10.1016/s0968-0004(00)01592-9

Song, H., Choi, J., Park, C. W., Shin, D. B., Kang, S. S., Oh, S. H., et al. (2015). Study of quality control of traditional wine using IT sensing technology. J. Korean Soc. Food Sci. Nutr. 44, 904-911. doi: 10.3746/jkfn.2015.44.6.904

Song, S. H. (2013). Analysis of microflora profile in Korean traditional Nuruk. J. Microbiol. Biotechnol. 23, 40-46. doi: 10.4014/jmb.1210.10001

Sosinska, G. J., de Koning, L. J., de Groot, P. W. J., Manders, E. M. M., Dekker, H. L., Hellingwerf, K. J., et al. (2011). Mass spectrometric quantification of the adaptations in the wall proteome of Candida albicans in response to ambient pH. Microbiology 157, 136-146. doi: 10.1099/mic.0.044206-0

Staniszewska, M., Bondaryk, M., Swoboda-Kopec, E., Siennicka, K., Sygitowicz, G., and Kurzatkowski, W. (2013). Candida albicans morphologies revealed by scanning electron microscopy analysis. Braz. J. Microbiol. 44, 813-821. doi: 10.1590/S1517-83822013005000056

Sudbery, P. E. (2011). Growth of Candida albicans hyphae. Nat. Rev. Microbiol. 9, 737-748. doi: 10.1038/nrmicro2636

Supek, F., Bošnjak, M., Škunca, N., and Šmuc, T. (2011). REVIGO summarizes and visualizes long lists of gene ontology terms. PLoS One 6:e21800. doi: 10.1371/ journal.pone.0021800
Van Zyl, J. H. D., Den Haan, R., and Van Zyl, W. H. (2016). Overexpression of native Saccharomyces cerevisiae ER-to-Golgi SNARE genes increased heterologous cellulase secretion. Appl. Microbiol. Biotechnol. 100, 505-518. doi: 10.1007/s00253-015-7022-2

Vollmeister, E., Schipper, K., Baumann, S., Haag, C., Pohlmann, T., Stock, J., et al. (2011). Fungal development of the plant pathogen Ustilago maydis. FEMS Microbiol. Rev. 36, 59-77. doi: 10.1111/j.1574-6976.2011.00 296.X

Wang, Y., Tang, L. J., Peng, X., Zhang, Z. B., Yang, H. L., Yan, R. M., et al. (2020). Transcriptome analysis of the dimorphic transition induced by $\mathrm{pH}$ change and lipid biosynthesis in Trichosporon cutaneum. J. Ind. Microbiol. Biotechnol. 47, 49-61. doi: 10.1007/s10295-019-02244-9

Yang, E., Chow, W. N., Wang, G., Woo, P. C. Y., Lau, S. K. P., Yuen, K. Y., et al. (2014). Signature gene expression reveals novel clues to the molecular mechanisms of dimorphic transition in Penicillium marneffei. PLoS Genet. 10:e1004662. doi: 10.1371/journal.pgen.1004662

Yang, S., Choi, S. J., Kwak, J., Kim, K., Seo, M., Moon, T. W., et al. (2013). Aspergillus oryzae strains isolated from traditional Korean Nuruk: fermentation properties and influence on rice wine quality. Food Sci. Biotechnol. 22, 425-432. doi: 10.1007/s10068-013-0097-6

Yang, S., Lee, J., Kwak, J., Kim, K., Seo, M., and Lee, Y. W. (2011). Fungi associated with the traditional starter cultures used for rice wine in Korea. J. Korean Soc. Appl. Biol. Chem. 54, 933-943. doi: 10.1007/bf03253183

Yeo, S. H., and Jeong, Y. J. (2010). Current trends and development a plan in the Korean Makgeolli industry. Food Sci. Ind. 43, 55-64.

Zhang, Q., Tao, L., Guan, G., Yue, H., Liang, W., Cao, C., et al. (2016). Regulation of filamentation in the human fungal pathogen Candida tropicalis. Mol. Microbiol. 99, 528-545. doi: 10.1111/mmi.13247

Zhu, L. B., Wang, Y., Zhang, Z. B., Yang, H. L., Yan, R. M., and Zhu, D. (2017). Influence of environmental and nutritional conditions on yeast-mycelial dimorphic transition in Trichosporon cutaneum. Biotechnol. Biotechnol. Equip. 31, 516-526. doi: 10.1080/13102818.2017.1292149

Conflict of Interest: The authors declare that the research was conducted in the absence of any commercial or financial relationships that could be construed as a potential conflict of interest.

Copyright (c) 2021 Farh, Abdellaoui and Seo. This is an open-access article distributed under the terms of the Creative Commons Attribution License (CC BY). The use, distribution or reproduction in other forums is permitted, provided the original author(s) and the copyright owner(s) are credited and that the original publication in this journal is cited, in accordance with accepted academic practice. No use, distribution or reproduction is permitted which does not comply with these terms. 